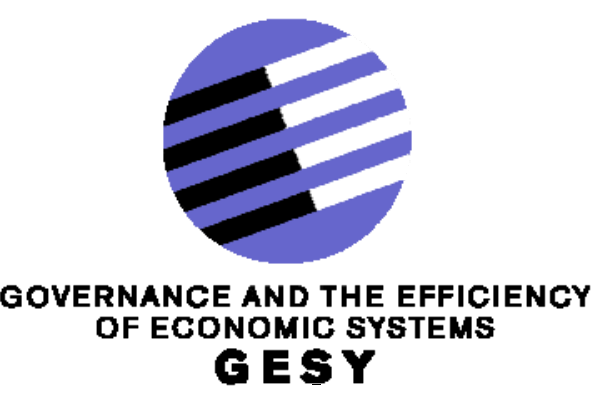

Discussion Paper No. 353

Evaluating Leniency with Missing Information on Undetected Cartels: Exploring Time-Varying Policy Impacts on Cartel Duration

Jun Zhou*

* Tilburg University, Netherlands

April 2011

Financial support from the Deutsche Forschungsgemeinschaft through SFB/TR 15 is gratefully acknowledged. 


\title{
Evaluating Leniency with Missing Information on Undetected Cartels: Exploring Time-Varying Policy Impacts on Cartel Duration*
}

\author{
Jun Zhou ${ }^{\dagger}$
}

February 2011, Revised April 2012

This paper examines the effects of European Commission's (EC) new leniency program on the EC's capabilities in detecting and deterring cartels. As a supplementary analysis, the US leniency is studied. I discuss a dynamic model of cartel formation and dissolution to illustrate how changes in antitrust policies and economic conditions might affect cartel duration. Comparative statics results are then corroborated with empirical estimates of hazard functions adjusted to account for both the heterogeneity of cartels and the time-varying policy impacts suggested by theory. Contrary to earlier studies, my statistical tests are consistent with the theoretic predictions that following an efficacious leniency program, the average duration of discovered cartels rises in the short run and falls in the long run. The results shed light on the design of enforcement programs against cartels and other forms of conspiracy. Journal of Economic Literature Classification Numbers: D43, K21, K42, L13. Keywords: evaluation of antitrust policies, leniency, time-varying policy effects, missing observations, sample selection bias.

\section{INTRODUCTION}

ILLEGAL cartels often enjoy long lives, even in jurisdictions where they are targeted for intensive investigation and harsh punishment. Cartels discovered by the European Commission (hereafter "EC") for the years 1985-2011 lasted, on average, more than eight years. International cartels

*This paper previously circulated under the title "Evaluating Leniency and Modeling Cartel Durations: Time-Varying Policy Impacts and Sample Selection". I benefited from discussions with Jan Boone, Estelle Cantillon, Urs Schweizer, Konstantino Tatsiramos, seminar participants at the 2011 Competition and Regulation European Summer School and Conference (especially George Deltas), the Sixth Annual Conference on Empirical Legal Studies, and Compass Lexecon. I thank Kani Karava at the European Commission Direct General Competition for providing data. Special thanks go to Iwan Bos, Eric van Damme, Dennis Gärtner, Joseph Harrington, Johannes Koenen, Daniel Krähmer, Nathan Miller, Valerie Suslow, and four anonymous referees for their insightful comments. Support from the German Research Foundation through SFB TR 15 is gratefully acknowledged. Any mistakes are my own.

${ }^{\dagger}$ Tilburg Law and Economics Center, Tilburg University, Warandelaan 2, 5037 AB Tilburg, the Netherlands (Email: econ.j.z@gmail.com) 
of the 90s sampled by Levenstein and Suslow (2011) take, on average, eight years to break up. Similar statistics have been reported by a number of recent studies. ${ }^{1}$ The duration of cartels is believed to depend on features of the cartel's self-policing mechanisms, such as information exchange and compensation (Levenstein and Suslow 2011; Zimmerman and Connor 2005), and those of market conditions, such as the volume and volatility of demand (Dick 1996; Suslow 2005) or the number of buyers (Dick 1996; Zimmerman and Connor 2005). Less well understood is whether antitrust policies can have an influence on cartel duration, and how to empirically evaluate the efficacy of the policies. ${ }^{2}$ Questions about the policies' efficacy are inherently difficult to address because of the potential sample selection bias from only observing the detected cartels (Levenstein and Suslow 2006; Harrington 2006b, 2008; Harrington and Chang 2009; Miller 2009; Brenner 2009) and the ambiguity regarding the long-run influences of policy intervention (Harrington and Chang 2009; Brenner 2009). But the analysis can shed light on the evaluation and design of enforcement programs against cartels and other forms of conspiracy.

This paper provides an empirical evaluation of the EC's new leniency program. The program commits the EC to the lenient treatment of early cartel confessors. In particular, it grants complete immunity from fines to the first participant in a cartel to inform the EC of the cartel, provided that an investigation into the alleged cartel has not already started. It also offers discretionary fine reductions to conspirators that denounce the cartel when an investigation is already underway. The key question addressed here is how to assess the deterrent effect of such a program on the population of cartels when information from undiscovered cartels is not available. This is worthwhile because, on the one hand, such programs have become increasingly popular instruments for destabilizing existing cartels and deterring new cartels in many jurisdictions around the world (OECD 2002, 2003) and have enjoyed proven success in the U.S. (Miller 2009); On the other hand, a burgeoning empirical literature (Brenner 2009; De 2010) is ambiguous about the efficacy of the EC's leniency. Because the EU and US leniency programs are similar in some important respects but different in others, ${ }^{3}$ conclusion about the performance of the former may not be drawn directly from that of the latter.

I structure the empirical analysis by adapting Harrington and Chang's (2009) model of dynamic cartel formation and dissolution where an industry of firms interact repeatedly over

\footnotetext{
${ }^{1}$ An excellent survey of this literature can be found in Levenstein and Suslow (2006).

${ }^{2}$ The exception is Miller (2009).

${ }^{3}$ For example, cartel ringleaders can apply for amnesty in the E.U., whereas in the U.S. they are excluded. Another related issue is that the U.S. has a plea bargain system that the E.U. lacks where it is possible for cartel participants to receive fine reductions through a plea agreement instead of leniency application.
} 
an infinite time horizon. Absent antitrust intervention, there is a "marginal industry" in which firms are indifferent between collusion and competing because the short-run gain of cheating for each firm equals its long-run benefit from colluding. An efficacious antitrust innovation works its effect by increasing a firm's short-run benefit from cheating to a level that exceeds its long-run gains from colluding. In this way, the policy-innovation moves the "marginal type" from a population of sustainable, longer-lived cartels to a population of unstable, shorter-lived ones. The model generates intuitive predictions that can be used to assess the efficacy of antitrust innovations (such as the leniency program): The impact of an efficacious policy on the duration of discovered cartels is time-dependent. In particular, following an increase in the detection capabilities of an antitrust authority, the marginal cartels immediately break up and the ensuing cartel discovery comes from a population of longer-lasting cartels. Because of such a sample selection effect, the average duration of discovered cartels increases in the short-run; In the long run, the duration decreases due to the enhanced overall deterrence.

The theoretical model is taken to 126 discovered cartels from the EC for the period December 18, 1985 to December 2011. The introduction of the new leniency program on February 19, 2002, provides an exogenous shock that identifies the impact of leniency on the duration of discovered cartels. Since that date, the grant of immunity has become automatic and the door of leniency applications has opened to late confessors. It is in these ways that the EC's new policy closely mimicked the US leniency. Therefore, I supplement the EC data with a comparable data set of cartel discoveries from the US Department of Justice (DOJ 1985-2005). Together, these data sets provide a basis for assessing the difference between cartel duration under the existing EC leniency regime and that absent the regime.

Reduced form, semiparametric hazard models are used and compared to alternative approaches. The models test whether cartel durations increase immediately following leniency introduction (consistent with enhanced detection) and whether durations subsequently fall below short-run levels (consistent with enhanced deterrence). Unlike earlier studies, my approach allows for a clear-cut separation of the short-run and the long-run impacts of leniency. I am able to control for economic conditions, cartel's self-enforcing mechanisms, and other factors that may influence cartel durations. By way of preview, the time series of cartel durations is consistent with the notion that the introduction of the new leniency program enhanced the detection and deterrence capabilities of the EC. The duration of discovered cartels increases immediately following the introduction of the leniency. The changes are statistically significant, large in magnitude, and robust to various specification and sample choices. The results indicate 
that the new leniency program may have the intended effects and lend credence to the EC's new policy.

The existing empirical literature of cartel duration has generally been based on a restrictive assumption: The effects of antitrust policies on cartel duration do not vary from the short run to the long run. A single duration elasticity was estimated where the short- and long-run impacts of changes in the policy environment on the hazard function - the conditional probability of cartel dissolution - are not isolated. This assumption will be relaxed here. The assumption is unsatisfactory because: first, that it precludes an analysis of the pattern of policy impact over time; and second that it gives rise to potentially biased estimates of the policy impact by confounding the short-term and the long-term effects. As Harrington and Chang and Miller (2009) have shown, the long-term impact on cartel stability of a policy-innovation may differ quantitatively and qualitatively from the short-term impact. ${ }^{4}$ An implication of this result is that no sensible inference can be drawn about a policy's efficacy without first separating the short-term from the long-term impacts.

Both Brenner (2009) and De (2010) empirically evaluate the impacts of the EC leniency programs and test Harrington and Chang's theory. The main difference between their approaches and mine is in the treatment of the short-run and long-run impacts. ${ }^{5}$ De does not differentiate the short-run from the long-run impacts. Brenner takes the first three years of the leniency program's existence as the short run (Brenner 2009, p. 643), despite lack of theoretical support for choosing any particular time length. I differentiate the impacts by cartel start date: In line with Harrington and Chang, the short-run impact arises only with cartels that started before leniency introduction; the long-run impact arises only with cartels born after the introduction. I directly derive a functional form for the hazard from Harrington and Chang's model. I then estimate this hazard function using semiparametric estimation techniques that are adjusted to account for the time-varying policy effects suggested by the theory. In contrast with Brenner's and De's where no supportive evidence for the theory was found, ${ }^{6}$ my empirical analysis

\footnotetext{
${ }^{4}$ See Harrington and Chang (2009), p. 1416 and Miller (2009), pp. 756, 760-62.

${ }^{5}$ Brenner (2009) and De (2010) do provide verbal discussions on the ambiguity of the long-run policy effects that are suggested by Harrington and Chang. But neither author has produced a formal analysis in this direction.

${ }^{6}$ Without producing an analysis that distinguishes the short-term from the long-term policy impacts, De claims that Harrington and Chang's theoretical predictions are not supported by the data (De 2010, p. 60). Brenner (2009) particularly states that his analysis restricts to testing the "short-term predictions" of Harrington and Chang's theory because the long-run predictions are ambiguous (see Brenner 2009, p. 641).
} 
demonstrates the theory's ability to reproduce many basic features of the data.

Additionally, the regression samples in Brenner and De are essentially single time series with one or two exogenous policy changes (the EC's 96 and 02 leniency programs). In contrast, I use both the EC and the DOJ data for which similar leniency programs are in place. Cross sectional variation as such may provide more robust identification (Miller 2007, 2009).

My analysis is subject to at least two important limitations, and the results should be interpreted with caution. The first limitation is that there are too few observations to yield reliable estimates about the long-run impact of the EC's 2002 leniency. To obtain reliable estimates, one needs an adequately number of cartels that are born after the leniency introduction. Only five EC cartels formed following the introduction. To remedy the problem, I supplement the EC data with the DOJ data. A sufficiently large number (40) of DOJ detected cartels formed in the period postdating the DOJ's policy innovation, admitting an analysis of the long-run impact; The second limitation is that the theoretical model requires one to draw inferences about the population of cartels using information from discovered cartels. The inferences are valid so long as the discovered cartels are characteristically representative. In the theoretical model, I assume that all cartels are detected with the same probability. In practice, however, the antitrust authority may focuses its resources towards dealing with cartel cases that surfaced through its leniency program.

My empirical results on the impacts of the EC leniency echo those of Miller (2009) and Levenstein and Suslow (2011), who study the impacts of the DOJ's amnesty. Miller specifies and explores an exogenous stochastic process of cartels though cartel formation and dissolution are not endogenized as in the present paper. ${ }^{7}$ Miller's results are consistent with those presented here because they suggest that guaranteed immunity for first-in leniency applicants is an important element for efficacious leniency. Levenstein and Suslow report descriptive statistics of international cartels that support Harrington and Chang's predictions about the amnesty's short-run impact though these predictions are not tested formally as in the current paper (Levenstein and Suslow 2011, p. 469). Other related empirical work includes that of Jacquemin et al. (1981), Marquez (1994), Dick (1996), Suslow (2005) and Zimmerman and Connor (2005) which documents the effects on cartel longevity of macroeconomic fluctuations, market conditions and other cartel characteristics.

My results may have important policy implications. Cartels harm consumer welfare and impede market efficiency. Although most jurisdictions around the world treat hardcore cartels

\footnotetext{
${ }^{7}$ Harrington and Chang (2009) made the same remark on Miller's (2009) model in relation to their theory.
} 
as "[t]he most serious ... violations of competition law" (OECD 2002b), the data analyzed here indicate that the EC detected hardcore cartels in more than 50 distinct industries across four continents over the sample period. The size of collusive overcharges is large: Boyer and Kotchoni (2011), for instance, estimate a median overcharge of over 13 percent, based on a meta-analysis of more than 1000 cartels; Using a survey of 674 hard-core cartels, Connor (2010) calculates a median overcharge of 25 percent.

Although the discussion to follow focuses primarily on cartel offenses, it demonstrates an empirical approach to the study of anti-crime policies that might be of broader interest. Cartels and other forms of crimes such as terrorism, narcotics violations, large-scale fraud, kidnapping, sexual violence and arms and human trafficking share in common an important characteristics: the offenders hide their activities and the victims do not always report. One observes therefore only discovered crimes. Analyzing the impact of a policy on the criminal activity is difficult because discovered crimes might be a small and characteristically unrepresentative sample of the population of crimes. Exploring the potentially time-varying pattern in average duration of observed crimes following a policy introduction should permit productive analysis of many anti-crime policies heretofore considered difficult.

The second section of the paper considers the theoretical foundation for empirical hazard models of the cartel formation and dissolution process. The implications of the model are explored empirically in the remaining sections. My sample of discovered cartels finds that the duration of collusion consistently reflects the determinants suggested by theory. Concluding remarks and possible extensions follow.

\section{THEORY}

\subsection{Industrial Behavior}

My starting point is Harrington and Chang's (2009) dynamic model of cartel formation and dissolution, within the framework of which I provide two slightly stronger results than Harrington and Chang (Theorems 7 and 8). My results, unlike Harrington and Chang's, can be directly corroborated in an empirical model of cartel durations. There is a population of oligopolistic industries. Time is discrete and $N$ identical firms play an infinitely repeated Prisoner's Dilemma in each industry. In each period, there is a stochastic realization of a market's profitability that is summarized by $\pi$. Each firm earns $\pi$ if they collude; if not, they compete and each firm earns $\alpha \pi$. Without loss of generality, I normalize $\alpha$ to 0 . A cartel participant earns $\theta \pi$ (with $\theta>1$ ) by unilaterally deviating from a collusive arrangement, where $\theta$ represents the value of 
deviation. $\theta$ is drawn from a distribution $F$ with support $[\underline{\theta}, \bar{\theta}]$ and positive continuous density $f$. At the beginning of each period, $\pi$ is observed by the firms prior to deciding how to behave. $\pi$ is given by a distribution $G$ with support $[\underline{\pi}, \bar{\pi}]$ and positive continuous density $g$. The firms discount time at the same rate; their discount factor is $\delta$ where $0<\delta<1$.

At the beginning of each period, industries are either cartelized or not. Industries that were cartelized at the end of the previous period are currently cartelized; Industries that were not cartelized at the end of the previous period have an opportunity to do so with probability $p$ (with $0<p<1$ ). If a cartel collapses at the end of a period - either due to self-defect or an antitrust intervention - then with probability $p$ the industry has an opportunity to re-cartelize in the next period. Let $y^{0}$ denote the present value of a firm's payoff when an industry is cartelized. An antitrust policy is a pair of parameters $\langle\sigma, \gamma\rangle$, where $\sigma \in(0,1)$ is the probability that the antitrust authority detects and penalizes a cartel at the end of each period. The (present value of) total amount of fines that a cartel participant pays is $\gamma y^{0}$, where $\gamma>0$ is the fine multiplier. Let $s(t ; \sigma, \theta)$ denote the steady-state share of cartels with a duration of $t$ periods in a type- $\theta$ industry under policy $\sigma$, where $t \in\{0,1,2, \ldots\} ; t=0$ means that industry $\theta$ is not cartelized; $1-\sum_{\hat{t}=0}^{t-1} s(\hat{t} ; \sigma, \theta)$ is the share that survive for at least $t$ periods. $^{8}$

\subsection{The Hazard Rate of Cartel Dissolution}

Now I derive theoretical predictions that can be tested empirically. They relate to the probability that a cartel survives for $t$ periods conditional on the event that the cartel survives for at least $t$ periods, i.e., the dissolution hazard of discovered cartels. An antitrust innovation, such as a leniency program, affects the hazard over time. I model an antitrust innovation as an exogenous change in the detection rate from $\sigma_{1}$ to $\sigma_{2}$ (with $\sigma_{2}>\sigma_{1}$ ). The steady-state dissolution hazard of discovered cartels in industry $\theta$ prior to the innovation is given by $h\left(t ; \sigma_{1}, \theta\right)=\frac{s\left(t ; \sigma_{1}, \theta\right)}{1-\sum_{\hat{t}=0}^{t-1} s\left(\hat{t} ; \sigma_{1}, \theta\right)}$, where $t \in\{1,2, \ldots\}$. The average steady-state dissolution hazard of discovered cartels prior to the innovation is given by:

$$
\tilde{h}\left(t ; \sigma_{1}\right)=\frac{\int_{\Theta_{1}} s\left(t ; \sigma_{1}, \theta\right) f(\theta) d \theta}{1-\int_{\Theta_{1}} \sum_{\hat{t}=0}^{t-1} s\left(\hat{t} ; \sigma_{1}, \theta\right) f(\theta) d \theta}, \quad t \in\{1,2, \ldots\},
$$

where $\Theta_{1}$ is the set of industries in which collusion can be sustained prior to the innovation. Rearranging (1), we have that $\tilde{h}\left(t ; \sigma_{1}\right)=\int_{\Theta_{1}}\left[h\left(t ; \sigma_{1}, \theta\right) \times \frac{\left(1-\sum_{t=0}^{t-1} s\left(\hat{t} ; \sigma_{1}, \theta\right)\right) f(\theta)}{\int_{\Theta_{1}}\left(1-\sum_{\hat{t}=0}^{t-1} s\left(\hat{t} ; \sigma_{1}, \theta\right)\right) f(\theta) d \theta}\right] d \theta . \tilde{h}\left(t ; \sigma_{1}\right)$

\footnotetext{
${ }^{8}$ For detailed derivations and formulations of the stead-state shares, see Harrington and Chang (2009), pp. 1409-10, and the online Appendix.
} 
is then the weighted average of $h\left(t ; \sigma_{1}, \theta\right)$, where the associated weight is the probability that a cartel with a duration of at least $t$ periods is of type $\theta$.

Let $\Theta_{2}$ denote the set of industries that are capable of sustaining collusion after the innovation. Due to Harrington and Chang, ${ }^{9}$ we have that, if $\sigma_{1}<\sigma_{2}$, then $\Theta_{1} \supseteq \Theta_{2}$. That is, raising the detection rate reduces the measure of the set of industries capable of sustaining collusion. After the innovation, formerly stable cartels in the set $\Theta_{1} \backslash \Theta_{2}$ collapse immediately and the distribution of industries shifts from $\frac{\left(1-\sum_{t=0}^{t-1} s\left(\hat{t} ; \sigma_{1}, \theta\right)\right) f(\theta)}{\int_{\Theta_{1}}\left(1-\sum_{t=0}^{t-1} s\left(\hat{t} ; \sigma_{1}, \theta\right)\right) f(\theta) d \theta}$ to $\frac{\left(1-\sum_{\hat{t}=0}^{t-1} s\left(\hat{t} ; \sigma_{1}, \theta\right)\right) f(\theta)}{\int_{\Theta_{2}}\left(1-\sum_{\hat{t}=0}^{t-1} s\left(\hat{t} ; \sigma_{1}, \theta\right)\right) f(\theta) d \theta}$. But in the short run durations stay unadjusted for the remaining cartels, i.e., their dissolution hazard is unchanged. The average dissolution hazard shifts, in the short run, from $\tilde{h}\left(t ; \sigma_{1}\right)$ to:

$$
\tilde{h}\left(t ; \sigma_{1}, \sigma_{2}\right)=\int_{\Theta_{2}}\left[h\left(t ; \sigma_{1}, \theta\right) \times \frac{\left(1-\sum_{\hat{t}=0}^{t-1} s\left(\hat{t} ; \sigma_{1}, \theta\right)\right) f(\theta)}{\int_{\Theta_{2}}\left(1-\sum_{\hat{t}=0}^{t-1} s\left(\hat{t} ; \sigma_{1}, \theta\right)\right) f(\theta) d \theta}\right] d \theta .
$$

The transition from the short run to the new steady state involves the duration of the surviving cartels adjusting in each industry: The industry-level hazard shifts from $h\left(t ; \sigma_{1}, \theta\right)$ to $h\left(t ; \sigma_{2}, \theta\right)=\frac{s\left(t ; \sigma_{2}, \theta\right)}{1-\sum_{\hat{t}=0}^{t-1} s\left(\hat{t} ; \sigma_{2}, \theta\right)}$. As a result, the average hazard readjusts, in the long run, to

$$
\tilde{h}\left(t ; \sigma_{2}\right)=\int_{\Theta_{2}}\left[h\left(t ; \sigma_{2}, \theta\right) \times \frac{\left(1-\sum_{\hat{t}=0}^{t-1} s\left(\hat{t}, \sigma_{2}, \theta\right)\right) f(\theta)}{\int_{\Theta_{2}}\left(1-\sum_{\hat{t}=0}^{t-1} s\left(\hat{t}, \sigma_{2}, \theta\right)\right) f(\theta) d \theta}\right] d \theta .
$$

We now arrive at the main results of the theoretical model:

Result 1 (Short-Run Effect of Raising Detection Rate). If $\sigma_{1}<\sigma_{2}$, then $\tilde{h}\left(t ; \sigma_{1}\right) \geq$ $\tilde{h}\left(t ; \sigma_{1}, \sigma_{2}\right)$ for all $t \in\{1,2, \ldots\}$. That is, an increase in the detection rate leads to an immediate fall in the average dissolution hazard of discovered cartels after an innovation.

Result 2 (Long-Run Effect of Raising Detection Rate). If $\sigma_{1}<\sigma_{2}$, then $\tilde{h}\left(t ; \sigma_{1}, \sigma_{2}\right) \leq$ $\tilde{h}\left(t ; \sigma_{2}\right)$ for all $t \in\{1,2, \ldots\}$. That is, after the immediate fall in the average hazard of discovered cartels following an increase in the detection rate, the hazard readjusts above the short-run levels.

Proofs are postponed to the online Appendix. But it is worth sketching the intuition here, because the comparative statics of this model are fairly intuitive and could result quite reasonably from a variety of dynamic models of cartel behavior. Result 1 of the theoretical model has the empirical analogue that an immediate increase in the duration of discovered cartels following the introduction of a more efficacious leniency program (captured by an increase in $\sigma$ ) is consistent with enhanced detection capabilities. This is because marginal cartels immediately

\footnotetext{
${ }^{9}$ See Harrington and Chang (2009), p. 1409.
} 
break up, and that the ensuing cartel discovery comes from a population of longer-lasting cartels; Result 2 has the empirical analogue that following the initial increase in cartel durations, a subsequent readjustment below short-run levels is consistent with improved deterrence capabilities. This is because, on one hand, the marginal cartels that are prone to quick dissolution would not form in the first place, entailing a rise in the average cartel durations observed; On the other hand, the formerly stable, long-lasting cartels dissolve earlier, leading to a decline in observed durations. In the long run, the latter effect eventually overcomes and dominates the former.

\section{Data}

Data for this study are taken from the complete set of published EC cartel decisions between December 18, 1985 to December 7, 2011. The EC data are supplemented with a comparable cartel discoveries data set from the US DOJ (1985-2005). The analysis relies primarily on the EC data because, first they are more comprehensive; and second, and more importantly, unlike in the DOJ data where cartel durations may be a part of an agreement reached in a plea-bargaining process (Miller 2009), durations in the EC data are more cleanly observed.

The EC data include 139 cartels decided by the EC, the Court of First Instance (CFI) and the European Court of Justice (ECJ). A rich variety of case-specific information is recorded in the data, including the start and end dates of a conspiracy, the affected product markets, and the level of fines. ${ }^{10}$ These are the key variables of interest in this paper. In order to isolate the effect of leniency from those of the other institutional changes, my analysis restricts to 126 cartels that dissolved before the publication of the White Paper on Damage Actions (April 2, 2008) - a major innovation in the EU's anti-cartel regime. ${ }^{11}$ I refer to the 126 cartels as my complete EU sample. A subsample of cartels - 106 cartels - of the complete EU sample are formed absent a leniency. They are referred as the pre-leniency EU sample.

Besides the problem of inadequate observations for estimating the long-run impact of leniency, the EC data suffers from a lack of reliable information on producer concentration. The variable has been shown to be an important determinant of cartel stability (Selten 1973) and

\footnotetext{
${ }^{10}$ Unless otherwise specified, all euro values throughout the paper are adjusted to $2010 €$ using standard measure of general price trends published by the OECD on the Producer Price Indices for prices, labor costs and interest rates of domestic manufacturing.

${ }^{11}$ The White Paper "suggests specific policy options and measures that would help giving all victims of EU antitrust infringements access to effective redress mechanisms so that they can be fully compensated for the harm they suffered". See http://ec.europa.eu/competition/antitrust/actionsdamages/index.html for details.
} 
the effects of leniency (Ellis and Wilson 2003). Omission of this variable could well bias some of the estimated effects of leniency and those of other predictors in my empirical analysis. In some cases, the EC reports market shares of cartel participants near the end of an infringement. However, using the information (e.g., De 2010) may give rise to endogeneity problems: ${ }^{12}$ Existing market shares may be results of cartel activities in deterring entries (Harrington 1989; Levenstein and Suslow 2011). Therefore, market concentration may increase as a cartel advances; Alternatively, the market shares of a cartel may decrease over the duration of an infringement if collusive profits attract more (non-conspiring) entrants into the market in question than would be in a more competitive environment (Sutton 1991, 1998; Symeonidis 2002; and Levenstein and Suslow 2010). Furthermore, apart from the US and Germany, data on concentration ratios and other summary measures of market structure are largely unavailable in official publications (Lyons et al. 2001, McCloughan and Abounoori 2003). Collecting data and constructing my own concentration ratios for each cartelized market are an enormous, if not impossible, task and are beyond the scope of the present analysis. But to remedy at least in part the potential model misspecification bias, I include the total number of participating cartelists during a cartel's entire course to control for, among other things, difference in producer concentration across the cartelized markets. Given that the sampled cartels usually capture the majority, if not all, of all the market shares, the number of cartel members may serve as a (imperfect but reasonable) proxy for the number of market competitors. In addition, although old participants may exit and new firms may join force in mid of an infringement, the total number of participated firms is invariant to a cartel's duration. Moreover, EU-wide and worldwide markets are likely to have more competitors than national markets; Some industry types (e.g., mining) are likely to feature higher concentration than others (e.g., wholesale and retail trade) for reasons such as existence of entry and exit barriers (Mann 1966; Martin 1979). Therefore, I include the scope of the geographic markets (as determined by the EC in its decision) and the type of industries as additional controls for concentration.

Cartel duration. The variables and model parameters are defined in Table 1, and the corresponding descriptive statistics are presented in Tables 2 and 3.

Besides reporting proven start dates of agreements, the EC sometimes reports suspected st-

\footnotetext{
${ }^{12}$ Information on the market shares of the cartel participants at the beginning of an infringement in the EC data are largely missing. Moreover, the EC generally distinguishes market share in sales volume and in sales value in its report.
} 


\begin{tabular}{|c|c|}
\hline & Definition \\
\hline Cartel & $\begin{array}{l}\text { An agreement or a series of agreements between competing firms or associations of firms } \\
\text { that constitutes a single infringement, according to the EC, of Art. } 101 \text { (formerly } \\
\text { Art. } 81 \text { and Art. } 85 \text { ) of the EC treaty. }\end{array}$ \\
\hline Start date & The start date of the first agreement between any two (or more) participants of a cartel. \\
\hline End date & $\begin{array}{l}\text { The ending date of the last agreement(s) between any two (or more) cartel partici- } \\
\text { pants that is reported in the EC's last published decision on the cartel. For cartels } \\
\text { that continued at least until the date of the EC's last published decision (hereafter } \\
\text { "decision date") and whose ending dates are (therefore) unpublished, it is set as the } \\
\text { decision date. }\end{array}$ \\
\hline
\end{tabular}

DEPEndent VARiables

DURATION The number of months between a cartel's start and end dates that is proven by documented evidence.

DURATION-2 The greater of [1] the number of months elapsed between a cartel's start and end dates that is suspected by the EC but without documented evidence; and [2] DURATION.

Antitrust Policies

LENIENCY-SR $\quad 0$ if a cartel ends before July 18, 1996; 1 if it ends after July 18, 1996, but before February 19, 2002; 2 if it ends after February 19, 2002.

LENIENCY-LR $\quad 0$ if a cartel formed before a leniency program; 1 otherwise.

FINES The average corporate cartel fines per infringement issued by the EC during the previous fiscal year.

\section{Macroeconomic Fluctuations, Firm Impatience and Industry Concentration}

INTEREST

Annual average (real) short-term interest rates, 3-month maturity. If the relevant geographic market consisted of multiple economic areas in multiple countries, it is the weighted average of the rates. The weight applied is the annual national GDP.

$\Delta \mathrm{GDP}$ Annual growth rate of the real domestic product of the relevant geographic market (according to the EC). If the relevant geographic market consisted of multiple economic areas in multiple countries, it is the weighted average of the rates. The weight applied is the annual national GDP.

PEAK-TROUGH 1 if a cartel ended during a peak-to-trough period of a business cycle; 0 otherwise. If the relevant geographic market consisted of multiple economic areas in multiple countries, it is the weighted average of the indicators. The weight applied is the annual national GDP.

POS-SHOCK Positive deviation of real annual GDP from trend line (using the Hodrick-Prescott filter). If the relevant geographic market consisted of multiple economic areas in multiple countries, it is the weighted average of the deviations. The weight applied 


\begin{tabular}{|c|c|}
\hline & Definition \\
\hline \multirow[b]{2}{*}{ NEG-SHOCK } & is the annual national GDP. \\
\hline & $\begin{array}{l}\text { Negative deviation of real annual GDP from trend line (using the Hodrick-Prescott } \\
\text { filter). If the relevant geographic market consisted of multiple economic areas in } \\
\text { multiple countries, it is the weighted average of the deviations. The weight applied } \\
\text { is the annual national GDP. }\end{array}$ \\
\hline FIRMS & The total number of competitors in a cartel during its entire course. \\
\hline INDUSTRY TYPE & $\begin{array}{l}\text { Categorical variable indicating the type of industry where a cartel operates. The indus- } \\
\text { try types are wholesale and retail trade; food, feed, tobacco and other agricultural } \\
\text { products; chemicals; transport; primary material; machinery, equipment and metal } \\
\text { products; and other products and services. }\end{array}$ \\
\hline MARKET SCOPE & $\begin{array}{l}\text { Categorical variable indicating the geographic scope of cartelized market. The scopes } \\
\text { are national, multinational (but less than EU-wide), EEA-wide or EU-wide, and } \\
\text { worldwide. }\end{array}$ \\
\hline
\end{tabular}

a. For these cartels, the EC's last published decision routinely orders the firms to refrain from the alleged agreement within a limited time scope.

art dates without support of documented evidence. Unless stated otherwise, throughout the paper I refer, as do Levenstein and Suslow (2011), to the start date of an agreement as its proven start date. Moreover, firms may participate in and leave a cartel at different dates; collusive agreements sometimes start in one region then spread over many regions (Levenstein and Suslow 2011). I refer, as do the EC, the CFI and Levenstein and Suslow (2011), ${ }^{13}$ to DURATION as the number of months elapsed from the proven start date of the first agreement to the end date of the last agreement between any two participants of a cartel. In robustness checks, I obtain similar results using suspected durations.

The straightforward way to differentiate the short-run and long-run effects of leniency, at least as it pertains to the result of Harrington and Chang, is by using cartels' start dates: The short-run effect arises only with cartels that formed prior to leniency introduction; while the long-run effect arises only with cartels that formed after leniency introduction. ${ }^{15}$ Panel A of Table 2 provides an overview for the average proven durations of the EC detected cartels by cartel's state and end dates.

\footnotetext{
${ }^{13}$ In various judgments, the Court of First Instance made it clear that it was not necessary, particularly in the case of a complex infringement of considerable duration, for the EC to characterize it as exclusively an agreement or concerted practice, or to split it up into separate infringements. ${ }^{14}$

${ }^{15}$ This method is due an insightful comment of Joseph Harrington.
} 
Table 2. EU Cartel Duration by Start and End Dates (in months)

Panel A: Means (Standard deviations)

\begin{tabular}{|c|c|c|c|c|c|}
\hline \multirow[b]{4}{*}{ End date } & \multicolumn{5}{|c|}{ Cartel's Start Date } \\
\hline & \multicolumn{3}{|c|}{ From } & \\
\hline & Before & Jul-18-96 to & After & All & \\
\hline & Jul-18-96 & Feb-19-02 & Feb-19-02 & Start Dates & Observations \\
\hline Before Jul-18-96 & $82(85)$ & - & - & $82(85)$ & 53 \\
\hline From Jul-18-96 to Feb-19-02 & $101(62)$ & $27(20)$ & - & $93(64)$ & 40 \\
\hline After Feb-19-02 & $190(99)$ & $47(16)$ & $31(20)$ & $118(103)$ & 33 \\
\hline All End Dates & $106(88)$ & $42(19)$ & $31(20)$ & $95(87)$ & \\
\hline Observations & 106 & 15 & 5 & & 126 \\
\hline \multicolumn{6}{|l|}{ Panel B: Medians } \\
\hline & \multicolumn{5}{|c|}{ Cartel's Start Date } \\
\hline & \multicolumn{3}{|c|}{ From } & & \\
\hline & Before & Jul-18-96 to & After & All & \\
\hline End date & Jul-18-96 & Feb-19-02 & Feb-19-02 & Start dates & Observations \\
\hline Before Jul-18-96 & 59 & - & - & 59 & 53 \\
\hline From Jul-18-96 to Feb-19-02 & 77 & 26 & - & 72 & 40 \\
\hline After Feb-19-02 & 152 & 47 & 33 & 77 & 33 \\
\hline All End Dates & 74 & 41 & 33 & 65 & \\
\hline Observations & 106 & 15 & 5 & & 126 \\
\hline
\end{tabular}

SourcE.- Author's calculations based on 126 cartel decisions by the European Commission and judgments of the Court of First Instance and the European Court of Justice for the period December 1985 to November 2011.

Note.- Durations reported in this table are the number of months elapsed between the proven start date and the end date of a cartel based on documented evidence. "Start date" refers to the start date of the first agreement between any two cartel participants.

Starting with the short-run effects and looking at cartels that formed prior to July 18, 1996 (column 1 of Panel A, Table 2), there is an average DURATION of 82 months for cartels that formed then failed in the pre-leniency period; The average DURATION increased by 23 percent following the introduction of the EC's 1996 Leniency (the average DURATION is 101 months for cartels that formed before but failed under the old leniency program) and more than doubled for cartels that formed absent leniency but failed under the new leniency regime.

Turning to the long-run impact of the EC's 1996 Leniency and looking at cartels that dissolved under the policy (row 2 of Panel A, Table 2), the average DURATION decreases from 101 months for cartels that formed absent leniency to 27 months for cartels born under the old leniency regime. There is a similar pattern associated with the long-run impact of the EC's 2002 Leniency (row 3 of Panel A, Table 2), where average DURATION is longer for cartels born absent leniency than for cartels born after the new leniency introduction (the average DURATION of cartels born under the new leniency is 31 months). Thus, evaluated 
within the framework of the theoretical model, the immediate increases in average DURATION following the leniency introductions are consistent with enhanced detection capabilities; and the subsequent falls in average DURATION are consistent with enhanced deterrence capabilities.

Panel B of Table 2 reports the median values that correspond to the entries in panel A. Because of the skewed distributions of the durations, the median values are below the means in most of the instances.

Institutional and economic environments. Three sets of explanatory variables are employed in the analysis. A first set of variables captures aspects of the institutional environment where cartels form and dissolve. By far, the most important is LENIENCY-SR - the variable that indicates the antitrust regime under which a cartel dissolves. It equals zero if a cartel dissolved before July 18, 1996, i.e., before a leniency regime was introduced in the EU; it equals one if the cartel failed after July 18, 1996 but before February 19, 2002, i.e., the period during which the 1996 Leniency Notice was in effect; it equals two if the cartel broke up after February 19, 2002, i.e., after the existing leniency regime replaced the 1996 regime. A second institution variable, FINES, controls for the severity of punishment. Similar to that in Miller (2009), the penalty variable is defined as the average corporate fines issued by the EC during the previous fiscal year. ${ }^{16}$

The remaining two sets of variables have been similarly defined and used in earlier empirical studies of cartel duration (Marquez 1994; Dick 1996; Suslow 2005; Zimmerman and Connor 2005). They reflect the possible variations in the market and macroeconomic environments where cartels operate. Some of these variables control for, at least in part, the potential heterogeneity in dissolution probabilities across cartels.

It is perhaps by now mother's milk to the industrial economists that in a repeated-game collusion is easier to sustain as players become more patient. The average annual interest rate with 3-month maturity - INTEREST — is the short-term market rate of interest generally available to borrowers. It is used as a presumptive measure of fluctuations in firms' discount factor.

Received industrial organization theory also suggests that business cycle timing may affect cartels' stability (e.g., Green and Porter 1984; Haltiwanger and Harrington 1991; Rotemberg

\footnotetext{
${ }^{16}$ Using total corporate fines during the previous year will not alter the results significantly. See the online Appendix for an analysis using the total corporate fines as a proxy for severity of punishment.
} 
Table 3: Descriptive Statistics

Panel A: Antitrust Policies; Market and Macroeconomic Conditions

\begin{tabular}{|c|c|c|}
\hline & Mean & Std. Dev. \\
\hline \multicolumn{3}{|l|}{ Antitrust Policies } \\
\hline LENIENCY-SR & .84 & .81 \\
\hline FINES (€ mln.) & 56.97 & 71.48 \\
\hline \multicolumn{3}{|c|}{ Market and Macroeconomic Conditions } \\
\hline INTEREST (\%) & 5.46 & 3.15 \\
\hline$\Delta \mathrm{GDP}(\%)$ & 2.46 & 1.35 \\
\hline PEAK-TROUGH (1=yes) & .52 & .47 \\
\hline POS-SHOCK (€ bln.) & $23,258.6$ & $51,616.46$ \\
\hline NEG-SHOCK (€ bln.) & $28,404.83$ & $52,431.91$ \\
\hline FIRMS & 96.61 & 679.3 \\
\hline Observations & \multicolumn{2}{|c|}{126} \\
\hline
\end{tabular}

and Saloner 1986). I test for the effects of observable business cycle fluctuations with two variables: [1] the real GDP growth rate ( $\Delta$ GDP); and [2] a dummy variable- PEAK-TROUGHindicating whether a cartel ends in a period of peak-to-trough. I distinguish between these business cycle measures, which are usually anticipated by the market players, and potentially unanticipated demand shocks. In order to capture the latter, I estimate a nonlinear trend in (real) GDP using the Hodrick-Prescott filter. The filter fits a smooth nonlinear trend curve to a time series by isolating the stationary cyclical component of the time series from its non-stationary trend component. I then calculate deviations from this nonlinear trend (POS-SHOCK and NEG-SHOCK) and examine the impact of such deviations on cartel stability.

There are a number of ways that the size of cartel membership - FIRMS - could affect or be associated with cartel stability. Besides reflecting (inversely) concentration, it may also influence, among other things, the costs of monitoring and coordinating a cartel (e.g., Stigler (1964), Dick (1996)). It is worth to note that the existence of some cartels with a large number of firms is not as paradoxical as it may appear: many cartels with a large membership are monitored and coordinated by a trade association. ${ }^{17}$

Finally, I include two categorical variables, INDUSTRY TYPE and MARKET-SCOPE, to control for the effects of omitted cartel-specific characteristics (e.g., price transparency, market

\footnotetext{
${ }^{17}$ Levenstein and Suslow (2011) make a similar remark on the large number of cartel participation. Brenner (2009) makes a similar remark on the role of trade association in monitoring and coordinating cartels.
} 
Table 3: Descriptive Statistics

Panel B: Industry Type and Market Scope

\begin{tabular}{|c|c|c|}
\hline & $\mathrm{N}$ & $\%$ \\
\hline \multicolumn{3}{|l|}{ INDUSTRY TYPE } \\
\hline Wholesale \& retail trade & 5 & 3.97 \\
\hline Food, feed, tobacco \& other agr. products & 9 & 7.14 \\
\hline Primary material & 15 & 11.9 \\
\hline Chemicals & 40 & 31.75 \\
\hline Machinery, equipment \& metal products & 23 & 18.25 \\
\hline Transport & 15 & 11.9 \\
\hline Other products \& services & 19 & 15.08 \\
\hline \multicolumn{3}{|l|}{ Market Scope } \\
\hline National & 33 & 26.19 \\
\hline Multinational & 18 & 14.29 \\
\hline EU-wide or EEA-wide & 54 & 42.86 \\
\hline Worldwide & 21 & 16.67 \\
\hline Observations & \multicolumn{2}{|c|}{126} \\
\hline
\end{tabular}

concentration, industry-specific cyclicality, etc.) that may be correlated with both dissolution likelihood and the included variables of interest. Table 3, Panel B reports the distribution of industry types and market scope.

\section{The Empirical Framework}

To analyze the influence of competition policy and that of economic environment on the duration of cartels, hazard models were estimated. My focus here is the effect of each exogenous characteristic of the cartel on the probability of cartel dissolution, conditional on cartel not having already collapsed, and holding other industry and institutional characteristics constant.

In what follows, I discuss two alternative empirical specifications and investigate the robustness of the results. The second specification is a generalization of the first. It should be stressed that the empirical models I am using are reduced form models and not structural models.

- Cox's (1972) semiparametric proportional hazard model is the most popular approach towards characterizing the hazard function $h(t ; \cdot)$. The model has been used in previous analysis of cartel durations (Zimmerman and Connor 2005; Levenstein and Suslow 2011; De 2010) and is flexible enough to account for potential inappropriate distribution assumptions 
that may be involved in parametric methods. ${ }^{18}$ The hazard function for cartel $i$ is

$$
h_{i}\left(t ; \mathbf{x}_{i}\right)=h_{0}(t) \times \exp \left(\mathbf{x}_{i}^{\prime} \beta\right)
$$

where $t$ is the elapsed time since the start of a cartel, $\mathbf{x}_{i}$ is a vector of observed explanatory variables. The parameter vector $\beta$ is the vector of coefficients, measuring the influence of observed characteristics. The term $\exp \left(\mathbf{x}_{i}^{\prime} \beta\right)$ shifts the baseline hazard function $h_{0}(t)$, and a positive coefficient indicates that the observed characteristics increase the dissolution hazard and reduce the cartel duration. The model is semiparametric in that the baseline hazard $h_{0}(t)$ is a nonparametric function of time, with the influence of other observable characteristics specified assuming a particular functional form. Furthermore, the model is a proportional hazard one since the ratio of the hazard function for any group with certain observed characteristics to that of the baseline hazard equals a constant, dependent only on the observed characteristics; i.e, $h(t) / h_{0}(t)$, the relative hazard function, is not time varying.

Suppose that there are $n$ observations and $k$ distinct cartel dissolution times. Further suppose that I can rank the dissolution times such that $t_{1}<t_{2}<\ldots<t_{k}$ where $t_{j}$ denotes the dissolution time for the $j$ th cartel. Furthermore, let $R_{j}$ denote the set of cartels that have not dissolved until time $t_{j}$. Then the probability that the $\ell$ th cartel will dissolve at time $t_{j}$ given that some cartel in set $R_{j}$ will collapse at time $t_{j}$ is

$$
\frac{h_{\ell}\left(t_{j} ; \mathbf{x}_{\ell}\right)}{\sum_{\tau \in R_{j}} h_{\tau}\left(t_{j} ; \mathbf{x}_{\tau}\right)}=\frac{\exp \left(\mathbf{x}_{\ell}^{\prime} \beta\right)}{\sum_{\tau \in R_{j}} \exp \left(\mathbf{x}_{\tau}^{\prime} \beta\right)}
$$

Taking the product of the conditional probabilities in (3) yields the partial likelihood function

$$
\mathcal{L}=\prod_{j}\left[\frac{\exp \left(\mathrm{x}_{j}^{\prime} \beta\right)}{\sum_{\tau \in R_{j}} \exp \left(\mathbf{x}_{\tau}^{\prime} \beta\right)}\right],
$$

with corresponding log-likelihood function

$$
\ln \mathcal{L}=\sum_{j}\left[\mathbf{x}_{j}^{\prime} \beta-\ln \sum_{\tau \in R_{j}} \exp \left(\mathbf{x}_{\tau}^{\prime} \beta\right)\right] .
$$

- Competing risks. A cartel can end for different causes: Besides "natural death" such as defection, independent discoveries by an antitrust prosecutor can also end a cartel. Therefore, estimation of the cartel dissolution hazard function from observed cartel duration times must also consider the censoring of duration for cartels ending due to antitrust interventions (Levenstein and Suslow 2011). For such cartels, we can only infer that collusion would have exceeded the observed cartel duration at the time of the cartel's dissolution.

\footnotetext{
${ }^{18}$ The advantages of using Cox (1972) model to analyze time to event data have been widely recognized. See, e.g., Kalbfleisch and Prentice (1980), Meyer (1990), and Perperoglou (2005).
} 
A popular choice towards the analysis of competition risks is using a stratified Cox model from augmented data (Lunn and McNeil 1995). Let $\phi$ denote a cartel's failure type where $\phi=0$ indicates those cartels collapsed in a natural death; $\phi=1$ indicates those cartels ceased by an antitrust intervention. The joint distribution of failure times and cause of failure is considered and the hazard function of a particular cause in the presence of all other causes is estimated. In the absence of ties (i.e., multiple cartel groups fail at the same $t_{j}$ ) the full partial log-likelihood is given by

$$
\ln \mathcal{L}=\sum_{j, \phi_{j}=0} \mathbf{x}_{j}^{\prime} \beta+\sum_{j, \phi_{j}=1}\left(\beta_{0}+\mathbf{x}_{j}^{\prime} \beta\right)-\sum_{j} \ln \left[\sum_{\tau \in R_{j}}\left(\exp \left(\mathbf{x}_{\tau}^{\prime} \beta\right)+\exp \left(\beta_{0}+\mathbf{x}_{\tau}^{\prime} \beta\right)\right)\right]
$$

where $\beta_{0}$ is a constant so that the baseline hazard functions for different types of cartel dissolution differ by a constant ratio.

Running standard Cox regression on the augmented data set gives the appropriate estimates of the regression coefficients, provided the model fit it good. The partial likelihood which results from the method is precisely the partial likelihood suggested by Kalbfleisch and Prentice (1980) for competing risks.

- Testing The Time-Varying Effects of Leniency. I conduct two statistical tests. In the first, I examine whether the dissolution hazard of discovered cartel decreases in the short run after the introduction of leniency. Result 1 of the theoretical model suggests that such a decrease is consistent with enhanced detection capabilities. Recall that the short-run effect of leniency arises only with cartels that formed prior to the leniency introduction. Therefore, I run regressions on the sample of cartels that formed prior to July 18, 1996. Because the regression model generates an immediate decrease in the hazard if an only if the coefficient of LENIENCY-SR is negative, I test the hypothesis:

$$
H_{0}: \beta_{L E N-S R} \geq 0 \text { versus } H_{1}: \beta_{L E N-S R}<0
$$

where $\beta_{L E N-S R}$ denotes the coefficient of LENIENCY-SR.

In the second test, I examine whether in the long run the hazard increases beyond the short-run levels. Result 2 of the theoretical model suggests such an increase is consistent with enhanced deterrence. Recall that the long-run effect of leniency arises only with cartels that formed after the leniency introduction. But as already mentioned above, there is a lack of observations on EC cartels that formed in that period. Therefore, I run regression on the time series of DOJ detected cartels that dissolved under the DOJ's 1993 leniency - a program that 


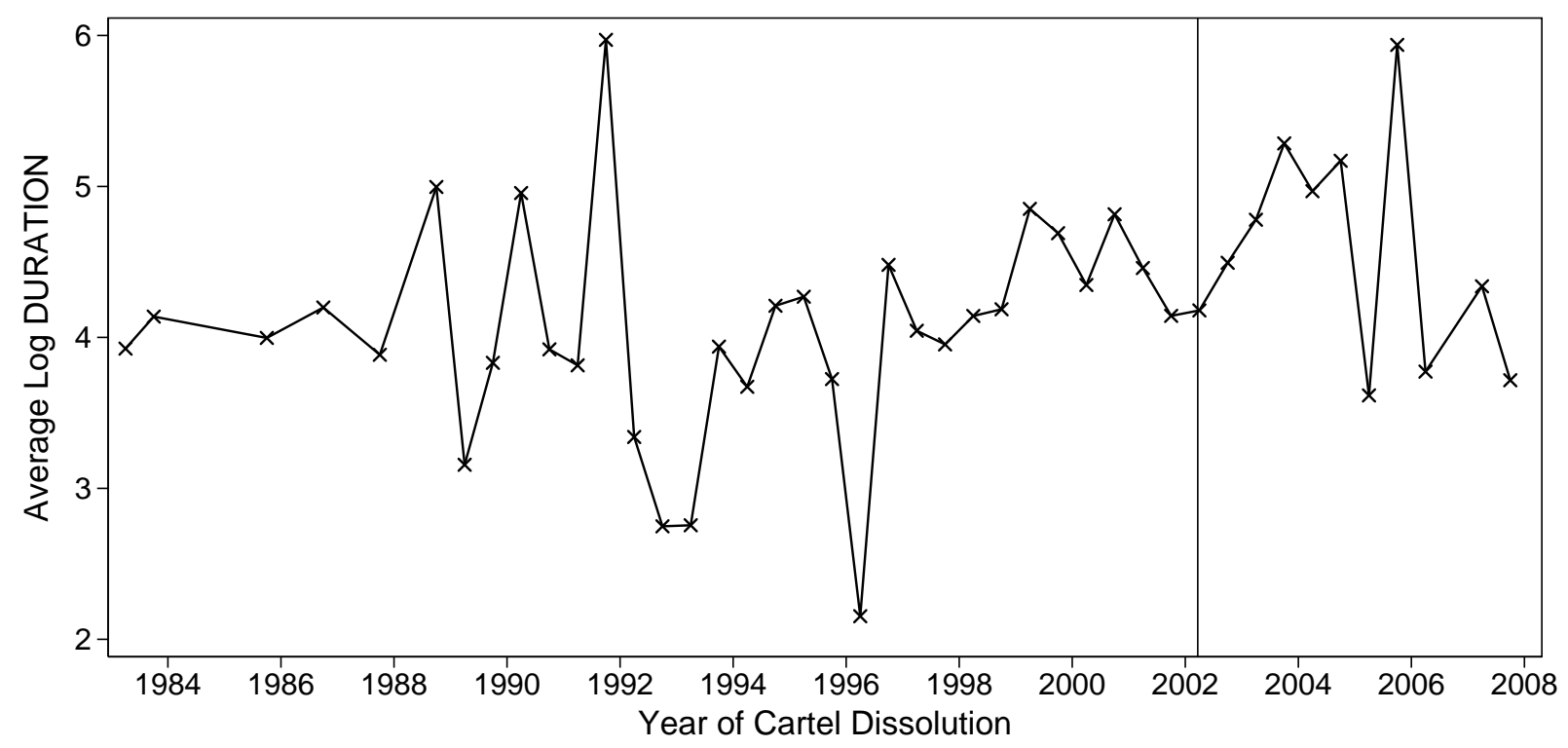

Figure 1. Semi-Annual Average Duration of The EC's Detected Cartels

Notes: The figure plots the semi-annual average log-transformed durations of 126 cartels decided by the EC, the Court of First Instance (CFI) and the European Court of Justice (ECJ) between December 18, 1985 to December 7, 2011 and dissolved within each six-month period from June 6, 1989 to October 17, 2007. The vertical bar marks the introduction of the new leniency program on February 19, 2002.

is similar to the EC's new leniency. Because the regression model generates an immediate increase in the dissolution hazard if and only if the LENIENCY-LR coefficient is positive, I test the hypotheses:

$$
H_{0}: \beta_{L E N-L R} \leq 0 \text { versus } H_{1}: \beta_{L E N-L R}>0
$$

where $\beta_{L E N-L R}$ denotes the coefficient of LENIENCY-LR.

\section{EMPirical Evidence}

\subsection{Duration of Cartel Dissolution}

- Graphical analysis. Figure 1 plots the semi-annual average (log-transformed) duration of detected cartels. Scales are log-transformed to reduce the effect of outliers. The vertical bar represents the introduction of the new leniency on February 19, 2002. DURATION averages 87 months in the 32 six-month periods preceding the new leniency. The average DURATION in the first eight periods immediately following leniency introduction - 121 months - is markedly higher. The remaining six periods average 97 months, about 28 percent lower than the first eight periods. The average duration in the second half of 1991 should be regarded as an extreme outlier rather than the norm: Only one cartel dissolved during that period; Moreover, in 68 out of the 93 cartels that dissolved before February 19, 2002, DURATION is below 100 months. 


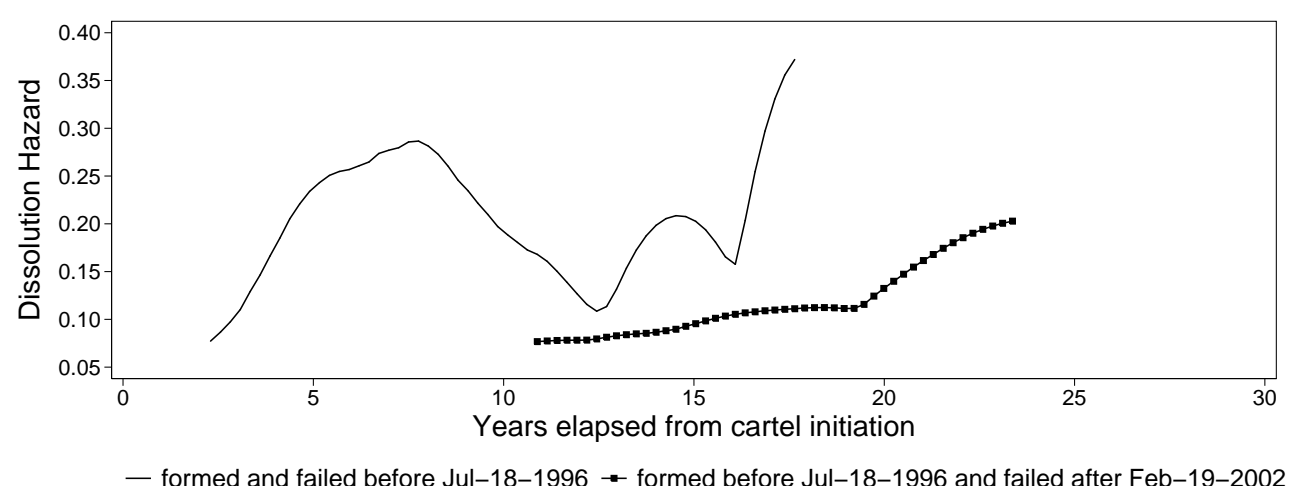

Figure 2. The Short-Run Impacts of The EC's 2002 Leniency Notes: The sample consists of 70 EC cartels that formed before July 18,1996 . The smooth line corresponds to
cartels that dissolved before July 18, 1996. The squared line corresponds to cartels that dissolved after Februa-
ry $19,2002$.

Next, I graph the non-parametric Kaplan-Meier hazard functions. The empirical hazard is the fraction of undissolved cartels at the start of a month which dissolves in that month. ${ }^{19}$ Using cartels born prior to July 18, 1996 but excluding cartels dissolved under the old leniency, these functions plot rates of cartel dissolution against the cartel durations. Figure 2 depicts the short-run movements of the empirical hazards following the introduction of the new leniency. The squared line (resp. smooth line) corresponds the short-run (resp. long-run) hazard profile under the new leniency (resp. absent leniency). As shown, the introduction of the new leniency immediately results in a hazard profile with lower probabilities of dissolution. This pattern becomes more pronounced as time elapses. Result 1 of the theoretical model suggests that such a change is consistent with enhanced detection capabilities.

At face value, the graphical analyses suggest that the short-run effect of the leniency predicted by Harrington and Chang's theory may be a reasonable approximation to actual impact. However, there is a reason to doubt this conclusion: The graphic analyses do not isolate the effects of leniency from those of changes in the economic and institutional environment that took place at roughly the same time. For example, the level of fines has increased steeply after 2002 (Russo et al. 2010). ${ }^{20}$ The next section will explore these empirical issues more rigorously.

Finally, notice that changes in the empirical hazards are hardly monotonic over time: Following an initial temporary rise, the long-run hazards absent leniency quickly fall. Then the hazards recover around year 12 and finally exceed initial levels. Temporarily putting aside the

\footnotetext{
${ }^{19}$ Formally, defining the risk set in month $m, R_{m}$, as the number of cartels not dissolved by the start of month $m$, and the number of break-ups in month $m$ as $S_{m}$, the Kaplan-Meier empirical hazard is defined as $S_{m} / R_{m}$.

${ }^{20}$ Russo et al. show that both the average fines per infringement and the total fines have increased sharply after 2002. See Russo et al. (2010), p. 20.
} 
empirical issue of whether these conflicting movements are due to random data outcomes or real economic forces, this graphic analysis suggests that a monotonic base-line hazard imposed by a Weibull specification, such as that in Brenner (2009), may not be suited to capture these movements.

- Regression analysis. Table 4 reports the Weibull (specification (1)) and Cox (specifications (2) and (3)) regression estimates of the coefficients on the explanatory variables. ${ }^{21}$ Our focus here is on the effects of leniency. The interpretation of the coefficients of the other factors will either be discussed very briefly or omitted here.

The regression analysis is performed in two steps. In the first, I run regressions on the complete EU sample and make the hazard rate a function of the antitrust policies and the economic conditions discussed in the previous sections. The impacts of leniency are estimated in the existing (in terms of model specification) framework within which the short- and longrun impacts are not isolated (in the sense of Harrington and Chang (2009)). The coefficient of LENIENCY-SR here is the average impact in the short and the long run on the hazard of introducing a leniency program. The purpose of this step is to show that a lack of account for the time-varying impacts of leniency could lead to a lack of empirical support for the efficacy of the policy.

In the second step (specification (3)), I use the same set of explanatory variables as in the previous specifications. But I exclude cartels that are born after the leniency introductions. As mentioned in the introduction, this enables me to isolate the short-run impact of the implementation of the leniency programs from the effects associated with the long-run adjustment process of cartel durations. The coefficient of LENIENCY-SR in this specification is the shortrun impact on the hazard of introducing leniency. If a statistically significant impact is found with this modification, then we can conclude that the rejection of significant policy effects in the first step was in fact due to the estimation biases stemming from a lack of isolation of long-run intervention effects.

For the regressions run on the complete EU sample, reported in columns 1 and 2 of Table 4, the coefficients of EC's 2002 LENIENCY-SR (The coefficients are -1.047 and -1.076 for specifications (1) and (2), respectively.) are statistically insignificant, suggesting that the EC's new amnesty may have failed to destabilize and deter cartels. These results, largely resembling

\footnotetext{
${ }^{21}$ The continuous variables are in terms of natural logs so that the coefficients in the equation equals the duration elasticities of the hazard rate with respect to the independent variables. In addition, I add one to all values before taking natural logs because some observations report zero values.
} 
Table 4. Hazard Model Estimates

\begin{tabular}{|c|c|c|c|}
\hline \multirow{3}{*}{ Specification } & \multicolumn{3}{|c|}{ Log(DURATION) } \\
\hline & (1) & $(2)$ & (3) \\
\hline & \multicolumn{2}{|c|}{ Complete EU Sample } & Pre-Leniency EU Sample \\
\hline \multirow[t]{2}{*}{ EC's 2002 LENIENCY-SR } & -1.047 & -1.076 & $-3.560^{* * *}$ \\
\hline & $(1.058)$ & $(1.144)$ & $(1.084)$ \\
\hline \multirow[t]{2}{*}{ EC's 1996 LENIENCY-SR } & -0.301 & -0.417 & $-1.026^{*}$ \\
\hline & $(0.565)$ & $(0.632)$ & $(0.605)$ \\
\hline \multirow[t]{2}{*}{ Log(FINES) } & 0.042 & 0.023 & 0.009 \\
\hline & $(0.078)$ & $(0.097)$ & $(0.106)$ \\
\hline \multirow[t]{2}{*}{ Log(INTEREST) } & -0.281 & -0.255 & -1.168 \\
\hline & $(0.882)$ & $(0.942)$ & $(0.977)$ \\
\hline \multirow[t]{2}{*}{$\log (\Delta \mathrm{GDP})$} & $-1.747^{* *}$ & $-1.824^{* *}$ & $-2.244^{* * *}$ \\
\hline & $(0.690)$ & $(0.736)$ & $(0.729)$ \\
\hline \multirow[t]{2}{*}{ Log(PEAK-TROUGH) } & -0.095 & -0.090 & -0.018 \\
\hline & $(0.423)$ & $(0.429)$ & $(0.532)$ \\
\hline \multirow[t]{2}{*}{ Log(POS-SHOCK) } & 0.189 & 0.202 & 0.257 \\
\hline & $(0.123)$ & $(0.139)$ & $(0.186)$ \\
\hline \multirow[t]{2}{*}{ Log(NEG-SHOCK) } & $0.224^{*}$ & $0.238^{*}$ & 0.307 \\
\hline & $(0.121)$ & $(0.141)$ & $(0.195)$ \\
\hline \multirow[t]{2}{*}{ FIRMS } & $-0.432^{* * *}$ & $-0.455^{* * *}$ & $-0.508^{* * *}$ \\
\hline & $(0.132)$ & $(0.144)$ & $(0.158)$ \\
\hline \multirow[t]{2}{*}{ Food, feed, tobacco \& other agr. products } & -1.154 & -1.003 & $-2.149^{* * *}$ \\
\hline & $(0.772)$ & $(0.757)$ & $(0.718)$ \\
\hline \multirow[t]{2}{*}{ Primary material } & $-1.649^{* *}$ & $-1.695^{* *}$ & $-1.909^{* *}$ \\
\hline & $(0.708)$ & $(0.743)$ & $(0.960)$ \\
\hline \multirow[t]{2}{*}{ Chemicals } & $-1.436^{*}$ & $-1.413^{*}$ & $-1.956^{* *}$ \\
\hline & $(0.736)$ & $(0.746)$ & $(0.837)$ \\
\hline \multirow[t]{2}{*}{ Machinery, equipment \& metal products } & $-1.997^{* *}$ & $-2.008^{* *}$ & $-3.418^{* * *}$ \\
\hline & $(0.828)$ & $(0.844)$ & $(0.909)$ \\
\hline \multirow[t]{2}{*}{ Transport } & $-3.066^{* * *}$ & $-3.035^{* * *}$ & $-3.649^{* * *}$ \\
\hline & $(1.058)$ & $(1.138)$ & $(1.285)$ \\
\hline \multirow[t]{2}{*}{ Other products \& services } & $-2.080^{* *}$ & $-2.030^{* *}$ & $-2.261^{* *}$ \\
\hline & $(0.867)$ & $(0.948)$ & $(0.994)$ \\
\hline \multirow[t]{2}{*}{ Multinational } & 0.421 & 0.501 & 0.291 \\
\hline & $(0.650)$ & $(0.757)$ & $(0.988)$ \\
\hline \multirow[t]{2}{*}{ EU-wide or EEA-wide } & 0.250 & 0.315 & -0.073 \\
\hline & $(0.559)$ & $(0.656)$ & $(0.786)$ \\
\hline \multirow[t]{2}{*}{ Worldwide } & 0.192 & 0.227 & -0.489 \\
\hline & $(0.796)$ & $(0.907)$ & $(1.064)$ \\
\hline \multirow[t]{2}{*}{ Constant } & -4.665 & & \\
\hline & $(3.879)$ & & \\
\hline Nonparametric baseline & no & yes & yes \\
\hline Sample size & 126 & 126 & 106 \\
\hline Number of failures & 68 & 68 & 55 \\
\hline Time at risk & 531.85 & 531.85 & 461.49 \\
\hline Log-pseudolikelihood & -37.77 & -254.41 & -186.67 \\
\hline
\end{tabular}

NotE.- Standard errors are robust to heteroskedasticity and are shown in parentheses. Omitted LENIENCY-SR category is "no leniency". Omitted industry category is "wholesale and retail trade". Omitted market scope category is "national" cartels. The source for these values is author's calculations based on 126 cartel decisions by the EC between December 1985 and December 2011. ${ }^{* *}$ significant at 1 percent level. ${ }^{* *}$ significant at 5 percent level. ${ }^{*}$ significant at 10 percent level. 
those of Brenner's (2009) and De's (2010) models, deserve scrutiny. One limitation of specifications (1) and (2) is that leniency programs, to the extent they have any impact, are constrained to generate time-average shifts in the log-hazard functions. But the theory (Results 1 and 2) suggests that effective antitrust innovations shift the hazard profile in opposite directions as time elapses. Therefore, deviations in hazard rate from pre-innovation levels may not be found when the movements are averaged out across time. Specification (3) isolates the long-run movements of hazards by restricting to cartels that are born prior to July 18, 1996. Harrington and Chang's model predicts that the time path of the hazard function shifts downwards immediately following the introduction of a more aggressive detection and conviction policy. The coefficient of EC's 2002 LENIENCY-SR in specification (3) is consistent with this proposition: The introduction of the new leniency immediately results in a hazard profile with a probability of dissolution that is approximately 34 times $(\exp \{3.56\}-1 \approx 34.16)$ lower than the pre-leniency levels. The effect is statistically significant and greater in absolute value than the corresponding estimates from specifications (1) and (2). I interpret the negative coefficient as evidence that the new leniency enhanced the EC's detection capabilities. There is a similar pattern associated with the impact of the old leniency where the coefficient of EC's 1996 LENIENCY-SR in specification (3) is negative, statistically significant and larger in absolute value than the corresponding estimates from specifications (1) and (2).

Received theory suggests that collusion becomes harder to sustain with increases in penalties and decrease in firms' patience. The signs of the coefficients are generally consistent with these propositions. The coefficient of my measure of the severity of penalties - FINES - is positive in specification (3). The coefficient of my measure of firms' patience - INTEREST - is negative. However, these effects are not statistically significant.

Turning to the measures of (anticipated) market demand fluctuations, the coefficient of $\triangle$ GDP is significantly negative in specification (3). This means that when the market is experiencing a demand growth, as represented by an increase in $\Delta$ GDP, the probability of dissolution is reduced. The result provides some support for the oligopoly theory which suggests that cartel stability is tied to business cycle timing. For stance, Haltiwanger and Harrington (1991) show that collusion becomes more difficult to sustain during recession when strong demand today signals strong demand tomorrow. An alternative explanation to the results above is that antitrust enforcement activity is countercyclical (Ghosal and Gallo 2001). Other demand fluctuation variables, however, do not exhibit a similarly large and significant impact on cartel stability. 
Finally, the significantly negative coefficient of FIRMS - my (inverse) measure of market concentration - is at odds with a number of earlier theoretical (e.g., Selten 1973) and empirical findings (e.g., Porter 1985; Vasconcelos 2004), and there are at least two explanations: The first is that concentrated industries invite closer scrutiny from an authority and increase the likelihood of detection (Levenstein and Suslow 2011). Second, a larger cartel membership, followed by wider industry coverage, enhances a cartel's ability to pool information within its membership and therefore improves the accuracy and cost effectiveness of cartel monitoring and detecting cheating on collusive agreements (Stigler 1964).

\section{Robustness Checks}

In this section I briefly describe exercises that I conducted to see if the results above are robust to my empirical modeling assumptions. Seven robustness concerns are addressed. They relate to (1) alternative measure of cartel duration, (2) confounding influences of the DOJ's antitrust interventions, (3) anticipation effect, (4) placebo interventions, (5) potentially time-dependent effects of penalties and economic conditions, (6) effects of the nature of infringement and cartels' organizational features, and (7) cross-sectional variations from the US DOJ data.

\subsection{Alternative Cartel Duration Measure}

An antitrust authority may not want to jeopardize its case by aiming to prove what it thinks is the correct start date. Instead, it may aim for an outcome that inflicts adequate punishment and results in a conviction. ${ }^{22}$ Therefore, the authority may not pursue an aggressive strategy with regards to proving long cartel duration. As a first robustness check, I test whether my results are robust to alternative measure of cartel duration. I rerun the specification in the third column of Table 4 but measure the speed of cartel dissolution by DURATION-2 - the lengths of cartels' lifetime that are suspected by the EC but not necessarily with supporting document evidence. The coefficients in the first column of Table 5 (specification (4)) show that my results are robust to alternative definition of cartel duration.

\subsection{Confounding Influences of the DOJ's Antitrust Interventions}

Twenty cartels in the pre-leniency EU sample operated not only in European but also in American markets. They are subject to American antitrust law rules and, obviously, their durations are likely to be affected by the DOJ's enforcement programs (e.g., the DOJ's 1993

\footnotetext{
${ }^{22}$ This point is due to the insightful comment of George Deltas.
} 
TABle 5. Robustness Checks (Suspected duration; DOJ's influence; anticipation effect; time-varying duration elasticities)

\begin{tabular}{|c|c|c|c|c|c|}
\hline \multirow{4}{*}{ Specification } & \multirow{2}{*}{$\frac{\log (\text { DURATION-2) }}{(4)}$} & \multicolumn{4}{|c|}{ Log(DURATION) } \\
\hline & & \multirow{3}{*}{$\begin{array}{c}(5) \\
\text { Pre-Leniency } \\
\text { EU Sample-3 }{ }^{b}\end{array}$} & \multirow{3}{*}{$\begin{array}{c}(6) \\
\text { Pre-Leniency } \\
\text { EU Sample }\end{array}$} & \multicolumn{2}{|c|}{$(7)$} \\
\hline & Pre-Leniency & & & Pre-Lenien & U Sample \\
\hline & EU Sample- $2^{a}$ & & & (BL) & $(\mathrm{TD})$ \\
\hline \multirow[t]{2}{*}{ EC's 2002 LENIENCY-SR } & $-3.842^{* * *}$ & $-3.330^{* *}$ & $-3.012^{* * *}$ & $-4.003^{* * *}$ & \\
\hline & $(1.043)$ & $(1.635)$ & $(1.166)$ & $(1.205)$ & \\
\hline \multirow[t]{2}{*}{ EC's 1996 LENIENCY-SR } & $-1.129^{*}$ & -0.585 & -0.960 & $-1.268^{*}$ & \\
\hline & $(0.604)$ & $(1.052)$ & $(0.617)$ & $(0.656)$ & \\
\hline \multirow[t]{2}{*}{ Log(FINES) } & 0.003 & 0.244 & -0.002 & -0.945 & 0.226 \\
\hline & $(0.107)$ & $(0.212)$ & $(0.107)$ & $(0.654)$ & $(0.151)$ \\
\hline \multirow[t]{2}{*}{ Log(INTEREST) } & -1.483 & -0.049 & -0.941 & 0.828 & -0.506 \\
\hline & $(0.860)$ & $(1.186)$ & $(1.036)$ & $(1.903)$ & $(0.453)$ \\
\hline \multirow[t]{2}{*}{$\log (\Delta \mathrm{GDP})$} & $-2.674^{* * *}$ & $-2.376^{* * *}$ & $-2.148^{* * *}$ & $-4.169^{* *}$ & 0.514 \\
\hline & $(0.754)$ & $(0.764)$ & $(0.798)$ & $(2.013)$ & $(0.482)$ \\
\hline \multirow[t]{2}{*}{ Log(PEAK-TROUGH) } & -0.009 & 0.541 & 0.027 & -1.152 & 0.315 \\
\hline & $(0.557)$ & $(0.874)$ & $(0.511)$ & $(2.786)$ & $(0.651)$ \\
\hline \multirow[t]{2}{*}{ Log(POS-SHOCK) } & 0.292 & 0.270 & 0.232 & 0.370 & -0.010 \\
\hline & $(0.201)$ & $(0.205)$ & $(0.184)$ & $(0.655)$ & $(0.137)$ \\
\hline \multirow[t]{2}{*}{ Log(NEG-SHOCK) } & 0.343 & 0.372 & 0.274 & 0.147 & 0.053 \\
\hline & $(0.214)$ & $(0.235)$ & $(0.186)$ & $(0.595)$ & $(0.124)$ \\
\hline \multirow[t]{2}{*}{ Log(FIRMS) } & $-0.549^{* * *}$ & $-0.534^{* * *}$ & $-0.488^{* * *}$ & $-0.582^{* * *}$ & \\
\hline & $(0.161)$ & $(0.188)$ & $(0.158)$ & $(0.157)$ & \\
\hline \multirow{2}{*}{$\begin{array}{l}\text { Food, feed, tobacco \& other } \\
\text { agr. products }\end{array}$} & $-2.201^{* * *}$ & $-2.216^{* *}$ & $-1.979^{* * *}$ & $-2.731^{* * *}$ & \\
\hline & $(0.691)$ & $(1.011)$ & $(0.760)$ & $(0.671)$ & \\
\hline \multirow[t]{2}{*}{ Primary material } & $-1.905^{* *}$ & $-1.988^{* *}$ & $-1.892^{* *}$ & $-2.280^{* *}$ & \\
\hline & $(0.902)$ & $(0.985)$ & $(0.917)$ & $(0.957)$ & \\
\hline \multirow[t]{2}{*}{ Chemicals } & $-2.180^{* * *}$ & $-1.879^{* *}$ & $-1.763^{* *}$ & $-2.423^{* * *}$ & \\
\hline & $(0.812)$ & $(0.953)$ & $(0.850)$ & $(0.939)$ & \\
\hline \multirow{2}{*}{$\begin{array}{l}\text { Machinery, equipment \& metal } \\
\text { products }\end{array}$} & $-3.586^{* * *}$ & $-3.769^{* * *}$ & $-3.272^{* * *}$ & $-3.869^{* * *}$ & \\
\hline & $(0.845)$ & $(1.189)$ & $(0.908)$ & $(0.943)$ & \\
\hline \multirow[t]{2}{*}{ Transport } & $-4.301^{* * *}$ & $-4.339^{* *}$ & $-3.560^{* * *}$ & $-4.118^{* * *}$ & \\
\hline & $(1.250)$ & $(1.800)$ & $(1.283)$ & $(1.257)$ & \\
\hline \multirow[t]{2}{*}{ Other products \& services } & $-2.936^{* * *}$ & $-2.660^{* *}$ & $-2.228^{* *}$ & $-3.120^{* *}$ & \\
\hline & $(1.022)$ & $(1.300)$ & $(0.987)$ & $(1.263)$ & \\
\hline \multirow[t]{2}{*}{ Multinational } & 0.154 & 0.931 & 0.368 & 0.381 & \\
\hline & $(0.910)$ & $(1.040)$ & $(0.972)$ & $(0.855)$ & \\
\hline \multirow[t]{2}{*}{ EU-wide or EEA-wide } & -0.011 & -0.054 & 0.053 & -0.152 & \\
\hline & $(0.771)$ & $(0.869)$ & $(0.762)$ & $(0.824)$ & \\
\hline \multirow[t]{2}{*}{ Worldwide } & -0.476 & -1.671 & -0.280 & -0.583 & \\
\hline & $(1.048)$ & $(1.097)$ & $(1.085)$ & $(1.095)$ & \\
\hline Sample size & 107 & 88 & 106 & & \\
\hline Number of failures & 55 & 37 & 55 & & \\
\hline Time at risk & 474.48 & 384.58 & 461.49 & & \\
\hline Log-pseudolikelihood & -183.91 & -118.40 & -188.32 & & \\
\hline
\end{tabular}

Note.- Standard errors are robust to heteroskedasticity and are shown in parentheses. Omitted LENIENCY-SR category is "no leniency". Omitted industry category is "wholesale and retail trade". The source for these values is author's calculations based on 126 cartel decisions by the EC between December 1985 and December 2011. *** significant at 1 percent level. ** significant at 5 percent level. * significant at 10 percent level. Omitted market scope category is "national" cartels.

${ }^{a}$ The sample consists of cartels that started prior to July 18, 1996 according to suspected start dates.

${ }^{b}$ The sample consists of cartels that started prior to July 18, 1996 according to proven start dates but excludes cartels that operated in US markets. 
Leniency Program) and efforts. To isolate the potentially confounding influences of the US antitrust interventions, I rerun the specification in the third column of Table 4 but exclude cartels that operated in American markets. The coefficient of EC's 2002 LENIENCY-SR in column 2 of Table 5 documents that my main conclusion is robust to isolating this subsample.

\subsection{Did Cartels Anticipate the New Leniency Program?}

The empirical strategy rests on the assumption that cartels did not anticipate the introduction of the new leniency. But an interesting feature of the data is that the durations actually spike prior to the introduction of the new leniency and one may naturally relate the spike to an anticipation effect. Indeed, it sometimes takes a considerable length of time before an EU legislation (e.g., the EC 's 2002 leniency) is adopted. During that time, through a public consultation and other deliberations, it was known to the interested parties that a policy change is likely on the way. Cartels might therefore have been paying attention to and reacted upon the potential leniency introduction before the EC formally adopts the leniency.

Figure 3 shows that my main findings are robust to the different treatments of particular pre-leniency periods. The dashed lines in Panels A, B, C and D alternately corresponds to the Kaplan-Meier hazard estimates when the new leniency were introduced 6, 12, 18 and 24 months sooner. The solid lines correspond to the estimated long-run hazard profile absent leniency. In each case, the predicated hazards after leniency fall below the pre-leniency levels. Therefore, to the extent that cartels anticipated the leniency introduction, the anticipated policy change immediately resulted in a hazard profile with lower probabilities of dissolution (consistent with enhanced detection).

As a more rigorous robustness check, I redefine LENIENCY-SR as if the EC's 2002 leniency program were introduced six months sooner (i.e., on August 19, 2001). Then I regress DURATION on the new LENIENCY-SR variable along with the other explanatory variables in column 3 of Table 4 . The resulting coefficient (-3.012) is negative, large in absolute value and again statistically significant at the 1 percent level (specification (6), column 3 of Table 5). Redefining LENIENCY-SR as if the new leniency were introduced 12 months sooner yields similarly large and significant coefficient for the effect of the leniency (as Table 8 in my online Appendix reports). Overall, therefore, the results lend statistical support for enhanced detection capabilities due to the introduction of the new leniency. ${ }^{23}$

\footnotetext{
${ }^{23}$ Alternatively, one might expect firms to delay their leniency applications until at least some time has elapsed since the introduction of the new leniency program. The empirical evidence cuts against this story. As early
} 
Panel A: New leniency intro. 6 mon. sooner
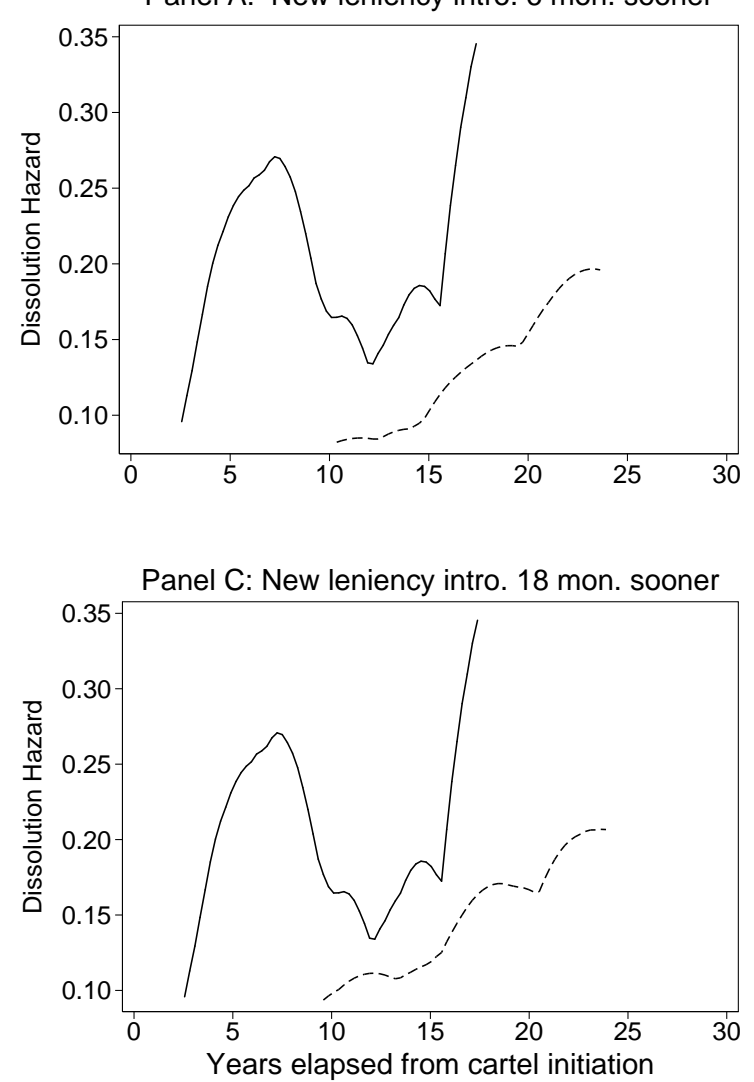

Panel B: New leniency intro. 12 mon. sooner
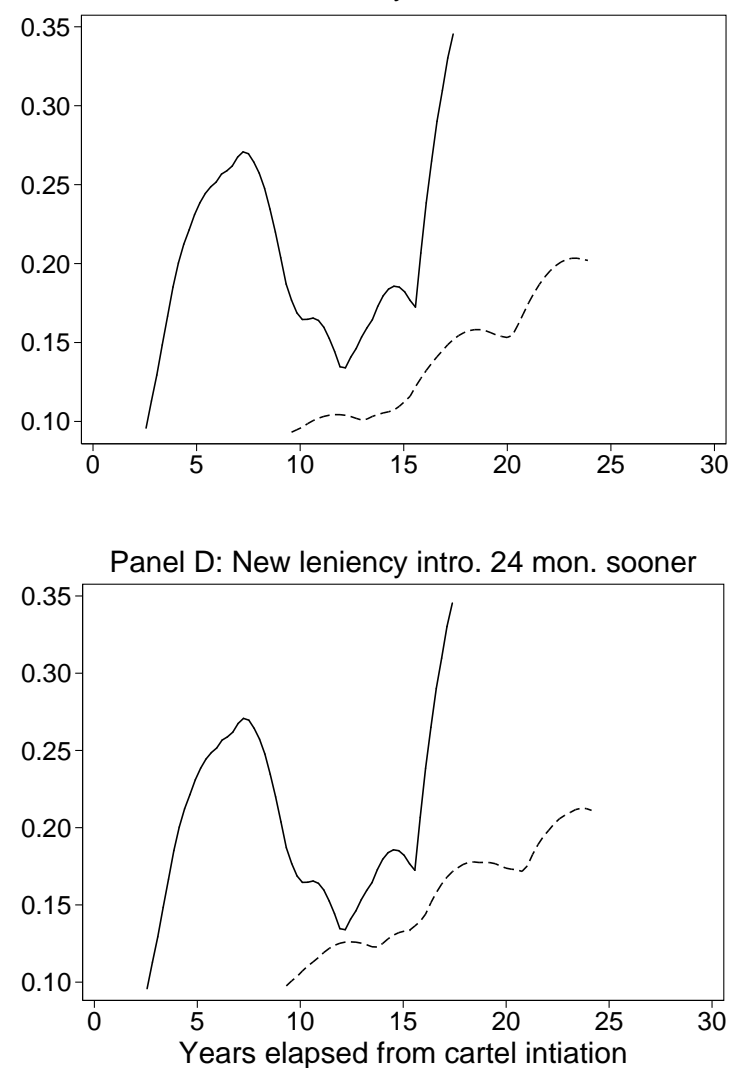

Figure 3. Short-Run Impact of the EC's 2002 Leniency when Cartels Anticipate the Leniency Introduction, Robustness Checks

Notes: The samples in panels A, B,C and D consists of 71, 74, 76 and 78 EC cartels that formed before July 18, 1996, respectively. The smooth lines in Panels A, B, C and D correspond to cartels that dissolved before July 18, 1996. The dashed lines in panels A, B, C and D alternately correspond to cartels that dissolved after August 19, 2001, February 19, 2001, August 19, 2000 and February 19, 2000.

\subsection{Leniency Programs versus Placebo Policies}

My empirical model imposes two exogenous breakpoints at the dates of leniency introductionJuly 18, 1996 and February 19, 2002. If alternative breakpoints - i.e., placebo policies - provide a better fit to the data, then one could argue that the relationship between leniency introduction and the time series of detected cartels is unlikely to be causal and that my results are driven by as on 19 February 2002, the EC received an application for leniency from Deltafina S.p.A. under the terms of the revised leniency. Moreover, the EC received leniency applications in more than 20 cases during the first year of the revised program, relative to only 16 cases during the previous 6 years combined (van Barlingen 2003; van Barlingen and Barennes 2005). Moreover, to the extent that firms delayed leniency applications, the average durations of discovered cartels that formed absent leniency but failed immediately prior to and after the introduction of the new leniency should be low (as opposed to the more gradual fall long after the introduction implied by the theoretical model). This fails to hold in the data: The average durations of discovered cartels that formed absent leniency but failed immediately prior to and after the leniency introduction are high. 
Panel A: Six-month periods

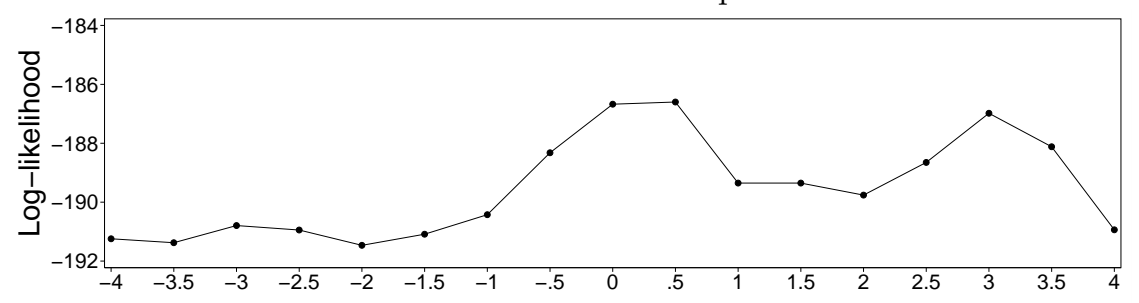

Panel B: Three-month periods

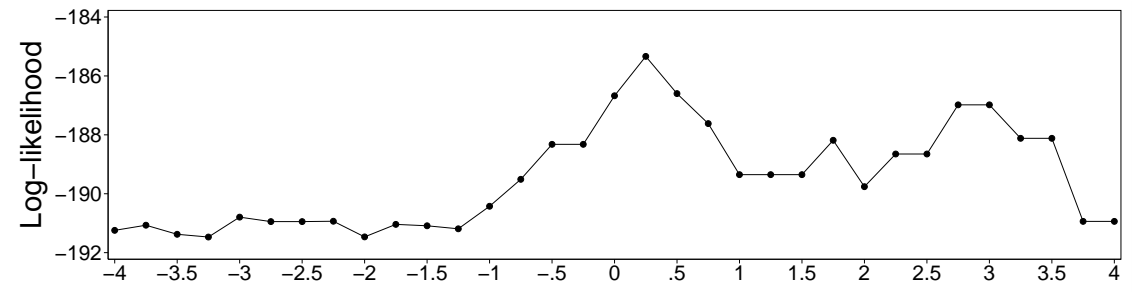

Panel C: Twelve-month periods

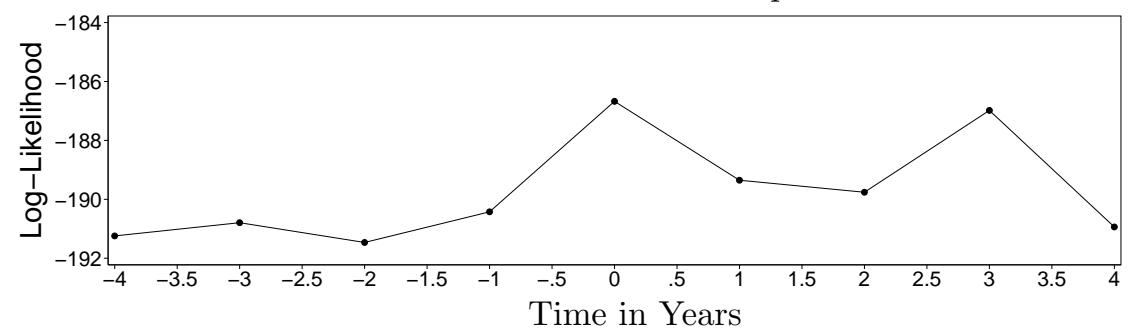

Figure 4. The EC's 2002 Leniency Program versus Placebo Interventions

Notes: Each point represents the maximized-likelihood of a Cox regression. The point located at zero at the horizontal axe is produced by breakpoints that correspond to the introduction of the EC's 2002 Leniency. The points to the left (resp. right) of zero are produced by placebo interventions that predates (resp. postdates) the introduction of the EC's 2002 Leniency.

misspecification. To see if this is the case, I re-run the regression model in column 3 of Table 4 but use alternative breakpoints in the data and compare the maximized log-likelihoods across the regressions.

Figures 4 depicts the results. Each point on the graphs represents the maximized loglikelihood of one regression specification. The point located at zero on the horizontal axes marks the maximized log-likelihood when the breakpoints are chosen at the leniency introductions. The points to the left (resp. right) of zero represent the log-likelihoods produced when the breakpoints are chosen before (resp. after) the introduction of the EC's 2002 leniency. Panel A uses six-month periods. As shown, the maximized log-likelihood produced by leniency $(-186.67)$ is greater than those produced by all but one placebo intervention that immediately follows the leniency introduction. The single offending placebo intervention corresponds to a sharp increase in DURATION of one cartel that dissolved in the first period after the leniency introduction. Panels B and C show that the results are similar when three-month and twelve-month periods are used. In the twelve-month case, the regression fit is globally maximal when the breakpoint 
is imposed at leniency introduction.

In Figure 5 of the online Appendix, I plot the log-likelihoods produced by breakpoints that are chosen before and after the introduction of the EC's 1996 leniency. The maximized loglikelihood produced by the old leniency is greater than those produced by all but one of the placebo interventions. Overall, the robustness check provides some support for the empirical specification.

\subsection{Time-Varying Effects of Fines and Economic Conditions}

To this point, my discussion of Cox models is fairly standard. Most applications make the initial hazard rate a function of explanatory variables and estimate a single duration elasticity. Earlier theory (e.g., Harrington 2004) and empirical evidence (Suslow 2005) suggest, however, that the impacts on cartel behavior of changes in institutional and economic environment may not be constant over time. Consequently, I generalize the usual proportional hazard specification by allowing the duration elasticity of each observation to vary with a vector of explanatory variables. The model being estimated now takes the form of $h_{i}\left(t ; x_{i}\right)=h_{0}(t) \exp \left(\mathbf{x}_{i}^{\prime} \beta(t)\right)$ where $h_{i}\left(t ; x_{i}\right)$ is the hazard rate at time $t$ for case $i$ with covariates $\mathbf{x}_{i}$. Following Stablein et al. (1981), I assume that $\beta(t)$ is a vector of linear functions of time. This is equivalent to adding an interaction term of $\mathbf{x}$ and time to the model, which was proposed by Cox (1972) to check the assumption of proportional hazards for the covariates. In the absence of ties (i.e., multiple cartel groups collapse at the same $t_{j}$ ) the full partial log-likelihood is given by

$$
\begin{aligned}
\ln \mathcal{L} & =\sum_{j, \phi_{j}=0} \mathbf{x}_{j}^{\prime} \beta\left(t_{j}\right)+\sum_{j, \phi_{j}=1}\left(\tilde{\beta}_{0}+\mathbf{x}_{j}^{\prime} \beta\left(t_{j}\right)\right) \\
& -\sum_{j} \ln \left[\sum_{\tau \in R_{j}}\left(\exp \left(\mathbf{x}_{\tau}^{\prime} \beta\left(t_{j}\right)\right)+\exp \left(\tilde{\beta}_{0}+\mathbf{x}_{\tau}^{\prime} \beta\left(t_{j}\right)\right)\right)\right],
\end{aligned}
$$

where, as before, $\phi=0$ (resp. $\phi=1$ ) indicates those cartels collapsed in a natural death (resp. an antitrust intervention). $\tilde{\beta}_{0}$ is a constant so that the baseline hazard functions for different types of cartel dissolution differ by a constant ratio.

The generalized model reported in columns 4 and 5 of Table 5 (specification (7)) allows variation in penalties and macroeconomic conditions to change both the slope and intercept of the relationship between the log-hazard function and the log of current duration. The coefficients reported under the heading "TD" (abbreviation for "time-dependence") gauge the effect of changes in penalties and economic environments on the slope, or duration elasticity, of this relationship. The coefficients reported under the heading "BL" (abbreviation for "baseline") 
generate parallel shifts in the log-hazard function. As shown, the generalization has no qualitative effect on my main result: The average duration of detected cartels increases immediately after the introduction of the new leniency.

\subsection{Nature of Infringement and Cartel's Organizational Features}

The hazard function reported in Table 6 (specification (8)) controls for types of infringement and cartel's organizational features as covariates. While some of the studies cited in the introduction include these variables, it may be argued that they are endogenous variables. The main point to extract from my analysis here is the robustness of the empirical regularities that following the introduction of the new leniency, the average duration of discovered cartels increases in the short run.

\subsection{Evidence from The United States}

The US DOJ's 1993 Leniency Program (August 10, 1993) facilitates further empirical evaluations of leniency. The EC's 2002 Leniency Notice, with its guarantee for full immunity for qualifying first-in applicants, aligns the EC's policy with that of the DOJ. In addition, the EC's new leniency - like the present US policy — replaced a regime in which immunity grants were discretionary. One could therefore apply the methods outlined in Sections 2 and 4 to gauge the impact of the 1993 Leniency Program on the ability of the DOJ to detect and deter cartels.

To this end, I use a subsample of Miller (2009)'s DOJ data and additional variables. By grouping the cartelists, Miller identifies a total of 342 distinct cartels from 809 information reports and 222 indictments. My analysis uses 334 cartels for which information on the approximate start and end dates of the conspiracy is available. A subsample of the DOJ data294 cartels - are formed before the introduction of the DOJ's new leniency. They are referred to as the pre-leniency DOJ sample. 86 cartels dissolved after the leniency introduction. I refer to them as the post-leniency DOJ sample.

- Descriptive statistics of cartel duration. In the online Appendix, I have a table (Table 9) that provides an overview for the average durations of the DOJ detected cartels by their start and end dates. The table shows that in the pre-leniency DOJ sample, the average duration of cartels that failed in the period preceding August 10, 1993 is markedly lower than that of cartels that failed after the leniency revision; Moreover, in the post-leniency DOJ sample, the 
TABle 6: Robustness Checks (Nature of Infringement and Cartel's Organizational Features)

\begin{tabular}{|c|c|c|c|}
\hline \multicolumn{2}{|l|}{ Specification } & \multicolumn{2}{|c|}{ 8) } \\
\hline \multicolumn{2}{|l|}{$\log ($ DURATION $)$} & \multicolumn{2}{|c|}{ Log(DURATION) } \\
\hline EC's 2002 LENIENCY-SR & $\begin{array}{c}-4.027^{* *} \\
(1.674)\end{array}$ & EU-wide or EEA-wide & $\begin{array}{l}-0.434 \\
(1.096)\end{array}$ \\
\hline EC's 1996 LENIENCY-SR & $\begin{array}{l}-0.987 \\
(0.806)\end{array}$ & Worldwide & $\begin{array}{l}-1.464 \\
(1.672)\end{array}$ \\
\hline $\log ($ FINES $)$ & $\begin{array}{c}0.078 \\
(0.122)\end{array}$ & PRICE FIXING & $\begin{array}{l}-0.347 \\
(1.116)\end{array}$ \\
\hline Log(INTEREST) & $\begin{array}{l}-0.795 \\
(1.203)\end{array}$ & MARKET SHARING & $\begin{array}{c}0.242 \\
(1.038)\end{array}$ \\
\hline $\log (\Delta \mathrm{GDP})$ & $\begin{array}{c}-2.392^{* *} \\
(1.011)\end{array}$ & BID RIGGING & $\begin{array}{l}-0.852 \\
(0.634)\end{array}$ \\
\hline Log(PEAK-TROUGH $)$ & $\begin{array}{l}-0.423 \\
(0.666)\end{array}$ & MONITORING & $\begin{array}{l}-0.730 \\
(0.816)\end{array}$ \\
\hline Log(POS-SHOCK) & $\begin{array}{c}0.259 \\
(0.287)\end{array}$ & RETALIATION & $\begin{array}{c}1.573^{* *} \\
(0.666)\end{array}$ \\
\hline Log(NEG-SHOCK) & $\begin{array}{c}0.340 \\
(0.271)\end{array}$ & PRICE LEADER & $\begin{array}{c}0.062 \\
(0.515)\end{array}$ \\
\hline $\log ($ FIRMS $)$ & $\begin{array}{c}-0.734^{* *} \\
(0.296)\end{array}$ & SIDE ARRANGEMENT & $\begin{array}{l}-0.080 \\
(0.607)\end{array}$ \\
\hline Food, feed, tobacco \& other agr. products & $\begin{array}{c}-4.653^{* * *} \\
(1.785)\end{array}$ & COMPENSATION & $\begin{array}{l}-0.002 \\
(0.561)\end{array}$ \\
\hline Primary material & $\begin{array}{c}-4.114^{* *} \\
(1.709)\end{array}$ & THREAT & $\begin{array}{c}0.385 \\
(0.969)\end{array}$ \\
\hline Chemicals & $\begin{array}{c}-2.963^{* *} \\
(1.412)\end{array}$ & RINGLEADER & $\begin{array}{c}-1.519^{* *} \\
(0.638)\end{array}$ \\
\hline Machinery, equipment \& metal products & $\begin{array}{c}-4.852^{* * *} \\
(1.586)\end{array}$ & RECIDIVISM & $\begin{array}{l}-0.233 \\
(0.696)\end{array}$ \\
\hline Transport & $\begin{array}{c}-3.754^{*} \\
(2.083)\end{array}$ & & \\
\hline Other products \& services & $-2.722^{*}$ & Sample size & 104 \\
\hline & $(1.629)$ & Number of failures & 54 \\
\hline Multinational & -0.405 & Time at risk & 451.10 \\
\hline & $(1.403)$ & Log-pseudolikelihood & -169.91 \\
\hline
\end{tabular}

NotE.- Standard errors are robust to heteroskedasticity and are shown in parentheses. Omitted LENIENCY-SR category is "no leniency". Omitted industry category is "wholesale and retail trade". Omitted market scope category is "national" cartels. PRICE FIXING=1 if any two members of a cartel agreed to fix prices or the rate of price increases or minimum prices, or to fix discounts and rebates, or to fix sales quota; 0 otherwise. MARKET SHARING=1 if any two members of a cartel agreed to allocate specific customers or types of customers, products, or territories among themselves; 0 otherwise. BID RIGGIN=1 if any two members of a cartel agreed to raise prices where purchasers acquired goods or services by soliciting competing bids; 0 otherwise. COMPNESATION=1 if members agreed on a compensation scheme; 0 otherwise. THREAT=1 if threat or coercion were used to induce participation in or compliance with an infringement; 0 otherwise. MONITORING $=1$ if sales information was exchanged for monitoring purpose; 0 otherwise. RETALIATION=1 if members agreed on retaliatory mechanisms; 0 otherwise. PRICE LEADER $=1$ if a member took the role of a price or market leader; 0 otherwise. SIDE ARRANGEMENT=1 if members had side arrangements (e.g., joint investment, technology sharing, exchange of product, etc.); 0 otherwise. RINGLEADER=1 the EC identified a ringleader; 0 otherwise. RECIDIVISM $=0$ if all members are first-time offenders; 1 if a member is a recidivist. The source for these values is author's calculations based on 104 cartel decisions by the EC between 1990 and April 2011. *** significant at 1 percent level. ** significant at 5 percent level. ${ }^{*}$ significant at 10 percent level. 
average duration of cartels that formed prior to the leniency revision is higher than that of cartels formed after the revision.

- Graphical analysis. The figure (Figure 6) that I present in the online Appendix plots the semi-annual average duration of detected cartels. The figure shows that the average duration of cartels that dissolved in the first eight periods immediately following the leniency introduction is markedly higher than that of cartels that formed and failed before the policy change; Moreover, the average duration long after leniency revision is lower than that of the first eight periods after the policy change.

Taking together and evaluated within the framework of the theoretical model, the descriptive statistics and the graphical analysis suggest that the increase in average duration in the short run around leniency revision is consistent with enhanced detection capabilities; and that the subsequent readjustment below short-run levels is consistent with enhanced deterrence capabilities.

- Regression analysis. I run two regressions: First, I consider the short-run effects of leniency. I rerun the model in column 3 of Table 4 on the sample of DOJ cartels that started before the introduction of the DOJ's new leniency and use additional variables. The variable DOJ LENIENCY-SR divides the pre-leniency DOJ sample into two groups: one consisting of cartels dissolved before the leniency introduction and the other of cartels dissolved after the leniency introduction. The coefficient of DOJ LENIENCY-SR is the short run effect of leniency on the hazard. Estimates of the coefficients are presented in columns 1 Table $7 .{ }^{24}$ It turns out that while the magnitudes of the effects of the antitrust policies vary, the main result of the previous sections holds: The estimated DOJ LENIENCY-SR coefficient of -0.486 corresponds to an immediate 63 percent $(\exp \{0.486\}-1 \approx 0.63)$ decrease in dissolution hazard and is statistically significant, consistent with enhanced detection.

Next, I consider the long-run effects of leniency. Column 2 of Table 7 shows that the regression results from the sub-sample of 86 cartels that dissolved after the leniency introduction. The variable DOJ LENIENCY-LR divides the sub-sample into two groups: one consisting of cartels started before the leniency introduction and the other of cartels started after the leniency introduction. The coefficient of DOJ LENIENCY-LR is the difference between the short- and long-run effects of leniency on the hazard. The estimated DOJ LENIENCY-LR coefficient is positive and statistically significant, and corresponds to a 9.11 times $(\exp \{2.314\}-1 \approx 9.11)$

\footnotetext{
${ }^{24}$ For brevity, the industry fixed effect coefficients are postponed to in the online Appendix.
} 
Table 7. Cox Regression Parameter Estimates of The DOJ Cartel Sample

\begin{tabular}{|c|c|c|}
\hline \multirow[b]{2}{*}{ Specification } & \multicolumn{2}{|c|}{ Log(DURATION-3) } \\
\hline & $(9)$ & $(10)$ \\
\hline & Pre-Leniency DOJ Sample & Post-Leniency DOJ Sample \\
\hline \multirow[t]{2}{*}{ DOJ LENIENCY-SR } & $-0.486^{*}$ & \\
\hline & $(0.260)$ & \\
\hline \multirow[t]{2}{*}{ DOJ LENIENCY-LR } & & $2.314^{* * *}$ \\
\hline & & $(0.375)$ \\
\hline \multirow[t]{2}{*}{ Log(FINES-2) } & $-0.473^{* * *}$ & $-0.298^{*}$ \\
\hline & $(0.133)$ & $(0.169)$ \\
\hline \multirow[t]{2}{*}{ Log(FIRMS) } & $-0.428^{* * *}$ & -0.104 \\
\hline & $(0.093)$ & $(0.180)$ \\
\hline \multirow[t]{2}{*}{ Log(INTEREST-2) } & -0.323 & $1.221^{* *}$ \\
\hline & $(0.281)$ & $(0.533)$ \\
\hline \multirow[t]{2}{*}{$\log (\Delta \mathrm{GDP})$} & 0.011 & -0.890 \\
\hline & $(0.211)$ & $(1.018)$ \\
\hline \multirow[t]{2}{*}{ PEAK-TROUGH } & 0.054 & -0.472 \\
\hline & $(0.287)$ & $(1.584)$ \\
\hline \multirow[t]{2}{*}{ Log(POS-SHOCK) } & 0.059 & 0.059 \\
\hline & $(0.101)$ & $(0.118)$ \\
\hline \multirow[t]{2}{*}{ Log(NEG-SHOCK) } & 0.053 & 0.010 \\
\hline & $(0.103)$ & $(0.146)$ \\
\hline \multirow[t]{2}{*}{ Regional } & $0.563^{* * *}$ & -0.118 \\
\hline & $(0.165)$ & $(0.410)$ \\
\hline \multirow[t]{2}{*}{ National } & 0.211 & -0.707 \\
\hline & $(0.212)$ & $(0.530)$ \\
\hline \multirow[t]{2}{*}{ International } & $0.770^{* *}$ & -0.418 \\
\hline & $(0.331)$ & $(0.560)$ \\
\hline Industry Fixed Effect & Yes & Yes \\
\hline Sample size & 294 & 86 \\
\hline Number of failures & 277 & 83 \\
\hline Time at risk & $1,040.06$ & 318.82 \\
\hline Log-likelihood & $-1,270.67$ & -262.85 \\
\hline
\end{tabular}

NotE.- Standard errors are robust to heteroskedasticity and are shown in parentheses. DURATION-3 is the number of months between a cartel's start and end dates that were plea-bargained. DOJ LENIENCY-SR equals one if a cartel dissolves in the period postdates August 10, 1993, and zero otherwise. DOJ LENIENCY-LR equals one if a cartel starts in the period postdates August 10, 1993, and zero otherwise. FINES-2 is the total corporate fines issued by the US DOJ during the previous fiscal year in 2005 dollars. INTEREST-2 is the annual average three month T-bill rate. Omitted geographic scope category is "local cartels". "Industry fixed effect" is a categorical variable indicating the type of industry where a cartel operates. The source for these values is author's calculations based on 334 cartel decisions by the US DOJ for the years 1985-2005. ${ }^{* * *}$ significant at 1 percent level. ${ }^{* *}$ significant at 5 percent level. ${ }^{*}$ significant at 10 percent level.

increase in the dissolution hazard from the short-run levels. I interpret the result as evidence that the new leniency enhanced the DOJ's deterrence capabilities. 


\section{Conclusion}

The social costs of cartel have motivated an extensive literature investigating the efficacy and design of anti-cartel policies. However, due to their illegal nature, cartels conceal their activities and one observes only discovered cartels. Because the discovered cartels might be a small and characteristically unrepresentative sample of the population of cartels, one cannot infer the efficacy of an antitrust-innovation on the population of cartels based on information gleaned from the discovered cartels without additional assumptions being made that may or may not be correct. This article takes one step to address the problem.

I adapt a model developed by Harrington and Chang (2009) where an industry of firms interact repeatedly over an infinite time horizon. An efficacious antitrust innovation increases a firm's short-run gains from unilateral deviation to a level that exceeds its long-run gains from colluding. In this way, some cartels would have been sustainable and long-lived in absence of the policy becomes unstable and shorter-lived. The model predicts that in the short-run, a more aggressive detection and conviction policy increases the average duration of detected cartels due to enhanced detection; In the long run, the average duration observed decreases due to enhanced deterrence.

Using data on discovered and prosecuted cartels from the EC, I estimate the influence of the EC's new corporate leniency program on the timing of cartel dissolution. My empirical work is the first that shows that, consistent with the theory, the duration of discovered cartels increases immediately following the introduction of a more efficacious leniency program and then falls below short-run levels.

Future empirical work should comprehensively address the issue of causality between leniency and cartel duration. This paper emphasizes the effect of leniency on duration, but there may be simultaneity: for example, it is sometimes thought that the origins of enhancements in the EC's detection and deterrence capabilities came from the US. The implementation of the DOJ's leniency programs in 1978 and 1993 followed an better understanding, in the US as well as in other jurisdictions, of cartel damages and duration. Similar policy innovations in the EU might have been triggered, at least partly, by such enhanced understanding. Though my analysis of the DOJ's leniency is free of the aforementioned endogeneity problem, a more rigorous empirical analysis to determine causality should be performed, ideally by having an instrumental variable for the EC's leniency introduction. Nevertheless, the analysis using the DOJ data finds that leniency has a causal impact on cartel duration, in line with the theory and my analysis of the EC time series of cartel duration. 
My regression samples are essentially two time series with three policy changes. Crosssectional variation could provide more robust identification, and the recent introduction of leniency programs by antitrust authorities at individual European member states may provide this variation in future research. Moreover, some cartels may have been discovered at member state level even though their operation may have been wider. The EC's leniency programs could well have an influence on these cartels although they have so far escaped the EC. Nevertheless, insofar as the effect of leniency - my main results - is concerned, the validity of the parameter estimates does not require that the regression sample include undetected cartels.

On balance, the evidence in favor Harrington and Chang's theory is strong. Harrington and Chang's dynamic model of cartel formation and dissolution does provide a simple but theoretically consistent way of analyzing cartel duration determinants, and it does receive some empirical support. My interpretation is that it is a promising way of bringing some understanding to the empirical regularities in this complex area.

\section{References}

[1] Akaike, Hirotugu (1974): “A New Look at The Statistical Model Identification," IEEE Transactions on Automatic Control, 19, pp. 716-23.

[2] Brenner, Steffan (2009): "An Empirical Study of The European Corporate Leniency Program," International Journal of Industrial Organization, 27(6), pp. 639-45.

[3] Boyer, Marcel and Kotchoni, Rachidi (2011): "The Econometrics of Cartel Overcharges," CIRANO Scientific Publication No. 2011s-35.

[4] Chen, Joe, and Joseph E. Harrington, Jr. (2007): "The Impact of the Corporate Leniency Program on Cartel Formation and the Cartel Price Path." In The Political Economy of Antitrust, edited by Vivek Ghosal and Johan Stennek. Elsevier.

[5] Connor, John M. (2010): "Price Fixing Overcharges: Revised 2nd Edition," available at: http://ssrn.com/abstract $=1610262$

[6] Cox, D. R. (1972): "Regression Models and Life-Tables (with Discussions)," Journal of Royal Statistical Society. Series B, 34, pp. 187-220.

[7] Cox, D. R. and Oakes, D. (1984): Analysis of Survival Data. London: Chapman and Hall.

[8] De, Oindrila (2010): "Analysis of Cartel Duration: Evidence from EC Prosecuted Cartels", International Journal of the Economics of Business, 17, pp. 33-65.

[9] Dick, A. R., (1996): "When Are Cartels Stable Contracts?", Journal of Law and Economics, 39, pp. 241-283. 
[10] Ellis, Christopher J., and Wesley W. Wilson (2003): "Cartels, Price-Fixing, and Corporate Leniency Policy: What Doesn't Kill Us Makes Us Stronger," available at: http://darkwing.uoregon.edu/wwilson.

[11] Ghosal, Vivek, and Joseph Gallo (2001): "The Cyclical Behavior of the Department of Justice's Antitrust Enforcement Activity," International Journal of Industrial Organization, 19, pp. 27-54.

[12] Grambsch, Patricia M. and Terry M. Therneau (1994): "Proportional Hazards Tests and Diagnostics Based on Weighted Residuals," Biometrika, 81, pp. 515-26.

[13] Haltiwanger, John, and Harrington, Joseph E., Jr. (1991): "The Impact of Cyclical Demand Movements on Collusive Behavior," RAND Journal of Economics, 22, pp. 89-106.

[14] Hammond, Scott D. (2010): "The Evolution of Criminal Antitrust Enforcement over the Last Two Decades," Speech at The 24th Annual National Institute On White Collar Crime.

[15] Harrington, Joseph E., Jr. (2004): "Optimal Cartel Pricing in the Presence of an Antitrust Authority," The RAND Journal of Economics, 35, pp. 651-73.

[16] Harrington, Joseph E., Jr. (2006a): “Corporate Leniency Programs and the Role of the Antitrust Authority in Detecting Collusion?", Competition Policy Research Center Discussion Paper, CPDP-18-E.

[17] Harrington, Joseph E., Jr. (2006b): "How Do Cartels Operate?", in Foundations and Trends in Microeconomics, 2, pp. 1-105.

[18] Harrington, Joseph E., Jr. (2008): "Optimal Corporate Leniency Programs," Journal of Industrial Economics, 56, pp. 215-246.

[19] Harrington, Joseph E., Jr. and Myong-Hun Chang (2009): "Modeling the Birth And Death of Cartelswith An Application to Evaluating Competition Policy," Journal of European Economic Association, 7, pp. $1400-35$.

[20] Harrington, Joseph E., Jr. and Andrzej Skrzypacz (2011): "Private Monitoring and Communication in Cartels: Explaining Recent Collusive Practices," American Economic Review, 101, pp. 1-25.

[21] Jacquemin, Alexis, Nambu, Tsuruhiko, and Dewez, Isabelle (1981): "A Dynamic Analysis of Export Cartels: The Japanese Case," The Economic Journal, 91, pp. 685-96.

[22] Kalbfleisch, J. D. and Ross L. Prentice (1980): The Statistical Analysis of Failure Time Data, New York: John Wiley \& Sons, Inc.

[23] Laird, Nan (1978): "Nonparametric Maximum Likelihood Estimation of a Mixing Distribution," Journal of American Statistical Association, 73, pp. 805-11.

[24] Levenstein, Margaret C., and Valerie Y. Suslow (2006): "What Determines Cartel Success?", Journal of Economic Literature, XLIV, pp. 43-95.

[25] Levenstein, Margaret C., and Valerie Y. Suslow (2011): "Breaking Up Is Hard to Do: Determinants of Cartel Duration," Journal of Law and Economics, 54, pp. 455-92.

[26] Lin, Y. (1991): "Goodness-of-Fit Analysis for the Cox Regression Model Based on a Class of Parameter Estimators," Journal of the American Statistical Association, 86, pp. 725-28. 
[27] Lunn, Mary and Don R. McNeil (1995): "Applying Cox Regression to Competing Risks", Biometrics, 51, pp. $524-32$.

[28] Mann, H. Michael (1966): "Seller Concentration, Barriers to Entry, and Rates of Return in Thirty Industries, 1950-1960," Review of Economics and Statistics, 48, pp. 296-307.

[29] Marquez, Jaime (1994): "Life Expectancy of International Cartels: An Empirical Analysis," Review of Industrial Organization, 9, pp. 331C41.

[30] Martin, Stephen (1979): "Entry Barriers, Concentration, and Profits," Southern Economics Journal, 46, pp. $471-88$.

[31] Meyer, Bruce D. (1990): "Unemployment Insurance and Unemployment Spells," Econometrica, 58, pp. $757-82$.

[32] Miller, Nathan H. (2009): "Strategic Leniency and Cartel Enforcement," American Economic Review, 99, pp. $750-768$.

[33] Organization for Economic Cooperation and Development (2002a): Fighting Hard Core Cartels: Harm, Effective Sanctions and Leniency Programmes.

[34] Organization for Economic Cooperation and Development (2002b): Hard Core Cartels - Harm and Effective Sanctions.

[35] Organization for Economic Cooperation and Development (2003): Hard Core Cartels. Recent Progress and Challenges Ahead.

[36] Perperoglou, Aris, Saskia le Cessie, and Hans C. van Houwelingen (2005): "Reduced-Rank Hazard Regression for Modelling Non-Proportional Hazards", Statistics in Medicine, 25, pp. 2831-2845.

[37] Porter, R. H. (1985): "On the Incidence and Duration of Price Wars," Journal of Industrial Economics, 33, pp. 415-26.

[38] Rosenbaum, Paul R., and Donald B. Rubin (1983): "The Central Role of the Propensity Score in Observational Studies for Causal Effects," Biometrika, 70, pp. 41-55.

[39] Russo, Francesco, Maarten Pieter Schinkel, Andrea Günster, Martin Carree (2010): European Commission Decisions on Competition — Economic Perspectives on Landmark Antitrust and Merger Cases, pp. 26-107. Cambridge: Cambridge University Press.

[40] Schoenfeld, D. (1982): "Partial Residuals for The Proportional Hazards Regression Model," Biometrika, 69, pp. 239-41.

[41] Selten, Reinhard (1973): "A Simple Model of Imperfect Competition, Where 4 are Few and 6 are Many." International Journal of Game Theory, 2, 141-201.

[42] Stigler, George J. (1964): “A Theory of Oligopoly," Journal of Political Economy, 72, pp. 44-61.

[43] Suslow, Valerie Y. (2005): "Cartel Contract Duration: Empirical Evidence from Inter-War International Cartels", Industrial and Corporation Change, 14, pp. 705-44.

[44] Sutton, John (1991): Sunk Costs and Market Structure: Price Competition, Advertising, and the Evolution of Concentration. Cambridge, Mass.: MIT Press. 
[45] Sutton, John (1998): Technology and Market Structure: Theory and History. Cambridge, Mass: MIT Press.

[46] Symeonidis, George (2002): The Effects of Competition: Cartel Policy and the Evolution of Strategy and Structure in British Industry. Cambridge, Mass.: MIT Press.

[47] van Barlingen, Bertus (2003): “The European Commission's 2002 Leniency Notice after One Year of Operation," Competition Policy Newsletter, 2, pp. 16-22.

[48] van Barlingen, Bertus, and Marc Barennes (2005): “The European Commission's 2002 Leniency Notice in Practice," Competition Policy Newsletter, 3, pp. 6-16.

[49] Vasconcelos, H. (2008): "Sustaining Collusion in Growing Markets," Journal of Economics and Management Studies, 17, pp. 973-1010.

[50] Vivek, Ghosal, Joseph E. Harrington Jr., and Johan Stennek. (2007): "Issues in Antitrust Enforcement." In The Political Economy of Antitrust, Vivek Ghosal and Johan Stennek (Editors), Contributions to Economic Analysis Series, Elsevier: Amsterdam, 2007, pp. 1-23.

[51] Zimmerman, Jeffrey E. and John M. Connor (2005): "Determinants of Cartel Duration: A Cross-Sectional Study of Modern Private International Cartels", available at SSRN: http://ssrn.com/abstract=1158577 